\title{
Combination Therapy for Cerebral Ischemia: Do Progesterone and Noscapine Provide Better Neuroprotection Than Either Alone in the Treatment ?
}

\author{
Manisha Kawadkar \\ VNS Group of Institutions \\ Avinash Singh Mandloi \\ VNS Group of Institutions \\ Nidhi Singh \\ VNS Group of Institutions \\ Rajesh Mukherjee \\ VNS Group of Institutions \\ Vipin Dhote ( $\checkmark$ vdhote@yahoo.com ) \\ VNS Group of Institutions
}

\section{Research Article}

Keywords: Stroke, BCCAO, HPLC, AUC, half-life, inflammation

Posted Date: July 27th, 2021

DOI: https://doi.org/10.21203/rs.3.rs-721093/v1

License: (c) (1) This work is licensed under a Creative Commons Attribution 4.0 International License.

Read Full License

Version of Record: A version of this preprint was published at Naunyn-Schmiedeberg's Archives of Pharmacology on January 6th, 2022. See the published version at https://doi.org/10.1007/s00210-02102187-y. 


\section{Abstract}

Purpose: Ischemic stroke presents multifaceted pathological outcomes with overlapping mechanisms of cerebral injury. High mortality and disability with stroke warrant a novel multi-targeted therapeutic approach. The neuroprotection with progesterone (PG) and noscapine (NOS) on cerebral ischemiareperfusion (I-R) injury was demonstrated individually, but the outcome of combination treatment to alleviate cerebral damage is still unexplored.

Methods: Randomly divided groups of rats $(\mathrm{n}=6)$ were Sham-operated, I-R, PG $(8 \mathrm{mg} / \mathrm{kg})$, NOS $(10 \mathrm{mg} / \mathrm{kg})$, and PG+NOS $(8 \mathrm{mg} / \mathrm{kg}+10 \mathrm{mg} / \mathrm{kg})$. The rats exposed to bilateral common carotid artery occlusion, except Sham-operated to investigate the therapeutic outcome of PG and NOS alone and in combination on I-R injury. Besides the alterations in cognitive and motor abilities, we estimated infarct area, oxidative stress, blood-brain barrier (BBB) permeability, and histology after treatment. Pharmacokinetic parameters like $\mathrm{Cmax}, \mathrm{Tmax}$, half-life, and $\mathrm{AUC}_{0-\mathrm{t}}$ were estimated in biological samples to substantiate the therapeutic outcomes of the combination treatment.

Results: We report PG and NOS prevent loss of motor ability and improved spatial memory after cerebral I-R injury. Combination treatment significantly reduced inflammation and restricted infarction; it attenuated oxidative stress, BBB damage, and improved grip strength. Histopathological analysis demonstrated a significant reduction in leukocyte infiltration with the most profound effect in the combination group. Simultaneous analysis of PG and NOS in plasma revealed enhanced peak drug concentration, improved AUC, and prolonged half-life; the drug levels in the brain have increased significantly for both.

Conclusion: We conclude that PG and NOS have beneficial effects against brain damage and, the coadministration further reinforced neuroprotection in the cerebral ischemia-reperfusion injury.

\section{Introduction}

Ischemic stroke disables more than it kills. High morbidity with stroke puts an enormous social and economic burden on the patient (Rajsic et al. 2019). The clinical spectrum of stroke is diverse and multiple molecular mechanisms drive neuronal damage after brain injury (Diaz-Arrastia et al. 2014; Gruenbaum et al. 2016). Exacerbated vascular permeability, elevated free radical generation, enhanced inflammatory reactivity, and ionic imbalance is some of the key pathobiological changes following brain injury (Jiang et al. 2017; Katan and Luft 2018) that culminates in the destruction of neurons and hamper brain functioning (Margaret et al. 2009). Therapeutic intervention to mitigate brain damage following ischemia focuses on restoration of obstructed blood flow to the brain but this sudden burst of oxygen paradoxically instigates cellular damage termed as "reperfusion injury". Tissue plasminogen activator (tPA), a thrombolytic agent is the only approved therapy following stroke and yield the best outcomes if administered within the "golden window" after stroke (Ali-Ahmed et al. 2019). The enormity of post-stroke consequences and high unmet medical needs presents an active research opportunity. 
Ischemic stroke presents multifaceted pathological outcomes with overlapping mechanisms of cerebral injury. Need to diffuse through the blood-brain barrier and alleviate neuronal damage warrants novel multi-targeted therapeutic approach (Chodobski et al. 2011; Jiang et al. 2017). Although, ischemic reperfusion injury causes blood-brain barrier (BBB) dysfunction which allows molecules that normally do not penetrate the BBB to enter into the brain, sustained concentrations of drug in the brain is the prerequisite for therapeutic effect (Chodobski et al. 2011). Achieving optimum availability of the drug in the brain has remained a challenge that hampered, to some extent, the successful translation of many promising neuroprotective agents to the clinic (O'Collins et al. 2006; Pardridge 2012; Thompson and Ronaldson 2014). Since ischemic reperfusion injury presents a wide spectrum of cellular damage, the monotherapy may not work as expected, combinational therapeutic approaches targeting different stages of an acute stroke may be an ideal strategy (O'Collins et al. 2011; Zhang et al. 2012; Liang et al. 2016). Despite the promise, the combination therapy needs optimization of effective dose, appropriate drug availability in the brain, and robust binding to multiple target proteins to extract desirable outcomes. Severe physiological responses to ischemic injury may vary the individual outcomes after stroke and hence pharmacokinetic profile of the therapeutic agents may provide vital inputs to evaluate the treatment outcomes.

As mentioned earlier, most treatment fails due to lack of transport across BBB; herein we designed a multipronged strategy using two agents (progesterone and noscapine) with proven ability to cross BBB and targeting more than one underlying mechanism responsible for brain damage. We also determined vital pharmacokinetic parameters in the brain and plasma to substantiate the pharmacological actions of the co-administration of both agents.

Progesterone (PG), a neurosteroid, exhibits neuroprotection effects by modulating the transcription of target genes by interacting with intracellular progesterone receptors (PR) and neural PR (Gruenbaum et al. 2016; Gaignard et al. 2017; Zhu et al. 2017; Moscote-Salazar et al. 2018; Guennoun et al. 2019). PG promotes regeneration of central myelin and regulates inflammation by microglia stabilization (Ghoumari et al. 2005; El-Etr et al. 2015). BBB restoration is mediated by downregulating the expression of aquaporin-4 (AQP-4) in the brain cortex (Wang et al. 2013) to reduce neuronal injury (González-Orozco and Camacho-Arroyo 2019). Similarly, noscapine extends its therapeutic effect on ischemic injury by antagonizing bradykinin receptors (Hashimoto et al. 2004; Arakawa et al. 2005; Khanmoradi et al. 2014). Noscapine, an alkaloid attenuates oxidative stress and inhibits inflammation to reduced cerebral damage in rats and prevent cell destruction in yeast (Rida et al. 2015; Kawadkar et al. 2021). It readily crosses BBB (Landen et al. 2004) and decreases brain edema against hypoxic/ischemic insult in neonatal rats (Mahmoudian et al. 2003). Moreover, it has been reported that oral administration of noscapine (NOS) to acute ischemic stroke patients improves clinical prognosis and reduces mortality rates (Mahmoudian et al. 2015).

It is imperative to give the rationale to select NOS for combination with PG in reperfusion injury. We contemplated various aspects of NOS like the ability to cross BBB; antagonism of bradykinin receptors; effect of bradykinin antagonism, ultimately reduced inflammation, on ischemia; high safety profile; its 
cytoprotective activity; ease of administration and inexpensive use for the treatment of other pathological conditions (Souza et al. 2003; Landen et al. 2004). Moreover, PG and NOS have been reported for their beneficial effect on the ischemic injury but both agents exhibited different mechanisms to reduce brain damage (Mahmoudian et al. 2003; Mahmoudian et al. 2015; Moscote -Salazar et al. 2018; Guennoun 2019).

Combining two promising neuroprotective agents (PG and NOS) we aimed at exploring the additive benefits of co-administration to potentiate therapeutic outcomes and estimating the pharmacokinetic profile responsible for its pharmacological actions. Earlier, pharmacokinetic studies have helped to explain and predict the distribution and metabolism of major components in vivo (Derendorf et al. 2000; Danhof et al. 2008; Ritter 2008; Gallo 2010). To the best of our knowledge only two studies reported pharmacokinetic profile of PG in the brain and plasma in experimental cerebral injury (Wong et al. 2012; Coomber and Gibson 2010) whereas, for the combination of PG with any other agent, no one has established pharmacokinetic profile to correlate its therapeutic effect on reperfusion injury.

We developed a simultaneous method of analysis for PG and NOS and to establish a correlation between efficacies and plasma drug concentration. The ability of both drugs to penetrate the brain could be an advantage to streamline the dosing schedule in post-stroke recovery using a combination approach. Given the proven neuroprotective potential of PG and NOS, pretreatment with co-administration may equip the brain to respond better or even extend the latter's neuroprotective effects (or vice versa) following reperfusion injury. Establishing the pharmacokinetic profile of PG and NOS immediately after cerebral injury and up to 1-2 days following reperfusion may provide valuable inputs to study therapeutic outcomes.

Hence, we investigated the combination of PG and NOS using the bilateral common carotid artery occlusion (BCCAO) model of ischemia-reperfusion (I-R) injury in rats. Further, the pharmacokinetic profile of both drugs, alone and in combination was estimated using plasma and brain samples to correlate drug concentrations with pharmacological effects following reperfusion injury in rats.

\section{Materials And Methods}

\subsection{Chemical and reagents}

Progesterone was obtained as a gift sample from Symbiotec Pharmalab Pvt. Limited, Indore. Noscapine was purchased from government opium and alkaloid works undertaking, Neeemuch, M.P. (Drug license no.20/75) as suggested by the chief controller, Government opium and alkaloid works, New Delhi. All other chemicals and reagents used in this work were of analytical grade and commercially availed from regular drug and reagents suppliers.

\subsection{Animals and ethical approval}


Wistar rats (250-280 g) were obtained from the Central Animal Facility of the institute and used for the experiment. Animals were housed in polypropylene cages and maintained under standard laboratory environmental conditions: temperature $25 \pm 2^{\circ} \mathrm{C}, 12$-h light and 12-h dark cycle with free access to food and water ad libitum. The experimental protocol (Protocol No. PH/IAEC/2K16/010) of the study was approved by the Institutional Animal Ethics Committee.

\subsection{Bilateral common carotid artery occlusion model}

The bilateral common carotid artery occlusion (BCCAO), the procedure was adapted from the method of (Iwasaki et al. 1989). After 7 days of pretreatment with PG and NOS, rats were anesthetized with chloral hydrate (350 mg/ kg ip). Subsequently, a ventral midline cervical incision was performed to expose both common carotid arteries (CCAs), and they were freed from their sheaths and carefully separated from the adjacent vagus nerves. Occlusion of CCAs reduced cerebral blood flow to about 70\% (Li et al. 2016). After $30 \mathrm{~min}$ of CCAs occlusion, reperfusion began by removing the carotid clips and was continued up to $24 \mathrm{~h}$ at which time measurements of the different parameters were made. It has been reported that BCCAO causes significant cerebral ischemia in rats (Yanpallewar et al. 2004).

\subsection{Study design for In-vivo studies}

Male Wistar rats weighing 250-280 g were randomly distributed into five groups containing 30 rats in each group and administered with respective treatment. Group 1, sham-operated control group, these animals received saline $2 \mathrm{ml} / \mathrm{kg}$, PO as a vehicle; group 2, ischemia-reperfusion (I-R) (i.e, BCCAO rats received saline vehicle); group 3, received progesterone (PG) $8 \mathrm{mg} / \mathrm{kg} P O ;$ group 4, received noscapine (NOS) $10 \mathrm{mg} / \mathrm{kg} \mathrm{PO}$; group 5, PG + NOS (8mg/kg $+10 \mathrm{mg} / \mathrm{kg})$ in combination., 7 days pre-treatment and on the day after surgery (8th day). Experiments were performed on five sets of animals $(n=6)$ within each group. The post-ischemic behaviors were recorded 3 days after reperfusion in the Morris water maze and an open field was also performed to assess spatial learni.0ng memory and general locomotor activities. The first set was used for observation of physiological parameters and determination of infarct volume. The second set was used for the estimation of behavioral parameters. The third set was used for the estimation of oxidative stress parameters: superoxide dismutase, glutathione reductase (SOD, GSH), lipid peroxidation, and myeloperoxidase (MPO) activity. The BBB permeability was evaluated in the fourth set, while a fifth set was for observation of histological changes (Fig. 1).

\subsubsection{Infarct analysis}

For infarct, analysis was performed in coronal slices $(2 \mathrm{~mm})$ of the promptly isolated brain and stained with $2 \%$ 2, 3, 5-triphenyltetrazoliumchloride (TTC) for $30 \mathrm{~min}$ at room temperature. A $10 \%$ formalin solution was used to fix the slices for the overnight period and evaluate the infarct area using Image $\mathrm{J}$ software 1.30V (http://www.rsb.into.nih/ ij). The infarct area was added together, for all sections, to obtain the total infarct area, which was multiplied with the thickness of the brain slice to obtain infarct volume per brain (mm3) and corrected for edema (Thiyagarajan and Sharma 2004). 


\subsubsection{Brain water content}

After the measurement of infarct volume, brain tissue was dried in an oven at $100^{\circ} \mathrm{C}$ for $24 \mathrm{~h}$ and reweighed to obtain the dry weight. The brain water content indicating brain swelling volume was expressed as (Schwab et al. 1997). The tissue water content is expressed as the percentage of the wet tissue weights as follows:

$\%$ of water content in brain $=$ Wet weight - Dry weight $\times 100 /$ Wet weight

\subsubsection{Evaluation of motor function}

The Rotarod is one of the most frequently used tests of motor function after $24 \mathrm{~h}$ of injury in the rats. The speed selector was set so that the roller rod makes $15 \mathrm{rpm}$. Before the test, each animal was given $1 \mathrm{~min}$ exposure to the moving rod. The animals were placed on the roller for $3 \mathrm{~min}$. Latency to fall from the rolling rod was observed. A normal animal could maintain its equilibrium for an indefinite period (Rogers et al. 1997).

\subsubsection{Morris water maze test}

The cognitive function of rats was assessed by using the Morris water maze test (MWM) as described earlier (Morris et al. 1982; Tiwari et al. 2009; Tuzcu and Baydas 2006). The test apparatus was a circular water tank (180 cm in diameter and $60 \mathrm{~cm}$ high) that was partially filled with water $\left(24 \pm 1^{\circ} \mathrm{C}\right)$. Full cream milk (1.5 I) was used to render the water opaque. The pool was divided virtually into four equal quadrants, labeled A-B-C-D. A platform (12.5 cm in diameter and $38 \mathrm{~cm}$ high) was placed in one of the four maze quadrants (the target quadrant) and submerged $2.0 \mathrm{~cm}$ below the water surface. The platform remained in the same position during training days (reference memory procedure). All animals followed this sequence for that session. Each rat was placed in the water facing the wall at the start location and was allowed $120 \mathrm{sec}$ to find the hidden platform. The animal was allowed a $20 \mathrm{sec}$ rest on the platform. The latency to reach the platform was recorded. If the rat was unable to locate the hidden platform, it was lifted out and placed on the platform for $20 \mathrm{sec}$. The procedure was repeated for all four start locations. Two sessions of four trials each were conducted on each day of testing separated by $4 \mathrm{~h}$. After that, the platform was removed and a probe trial (without platform) was conducted. Each rat was placed in the pool at the same randomly selected starting pole and the swimming path was observed and time spent in the quadrant of the pool which initially contained the platform was measured. On completion of the probe trial, a black platform that extended $1 \mathrm{~cm}$ above the surface of the water was placed in a quadrant other than that chosen for the submerged platform. Each rat was then given four trials of $120 \mathrm{sec}$ to locate it. The latency to reach the platform was recorded (working memory procedure) (Patil et al. 2015; Yanpallewar et al. 2004; Wang et al. 2017).

\subsubsection{The Open Field Test}

Locomotor function and anxiety were assessed using the open field test, as described previously (Lu et al. 2016). A square wooden open field $(44 \times 44 \times 32 \mathrm{~cm})$ was subdivided into 16 even squares with thin 
white stripes. Each mouse was placed next to the wall of the arena, facing away from the experimenter. Behavior was recorded for $10 \mathrm{~min}$. outcome measures were it was observed for the ambulations (number of squares crossed), the total period of immobility (in seconds), number of rearings, and groomings at the end of each trial, the arena was cleaned using $70 \%$ ethanol to prevent olfactory cue bias (Yanpallewar et al. 2004; Almahozi et al. 2019).

\subsubsection{Assessment of oxidative stress}

The brain tissue $(1 \mathrm{~g})$ was homogenized in ice-cold $10 \%$ trichloroacetic acid (TCA) using a tissue homogenizer. Malondialdehyde (MDA) levels were assayed as an index of lipid peroxidation by monitoring the formation of thiobarbituric acid-reactive substances at $532 \mathrm{~nm}$ and expressed as malondialdehyde (MDA) content, mmol MDA/mg of tissue protein (Slater and Sawyer 1971). Superoxide dismutase (SOD) activity was measured by the inhibition of pyrogallol autoxidation at $420 \mathrm{~nm}$ for 5 min (Marklund and Marklund 1974) one unit activity was determined as the amount of enzyme that inhibited the oxidation of pyrogallol by $50 \%$. Similarly, reduced glutathione (GSH) was determined using $5,5^{\prime}-$ dithiobis (2-nitrobenzoic acid) (DTNB) reagent at $412 \mathrm{~nm}$ and expressed as $\mu \mathrm{g}$ of GSH/mg of protein (Moron et al. 1979). Tissue protein was estimated in each sample with the method reported by Lowery et al. (1951).

\subsubsection{Evaluation of BBB dysfunction}

The integrity of BBB was investigated by Evans blue (EB) extravasation due to leakage in the brain. Permeability of the BBB was quantified as $\mu \mathrm{g}$ of $\mathrm{EB} /$ hemisphere and considered an index of vascular permeability. At the commencement of reperfusion, EB $(0.1 \mathrm{ml}$ of a $4 \%$ solution) was injected into the tail vein. The rat was anesthetized and perfused transcardially with $100 \mathrm{ml}$ heparinized saline solution (10 $\mathrm{IU} / \mathrm{ml}$ ) after reperfusion. Once sacrificed, the rat brain was removed. Rat Brain was homogenized in $1 \mathrm{ml}$ of $0.1 \mathrm{~mol} / \mathrm{I}$ PBS and then centrifuged at $1000 \mathrm{~g}$ for $15 \mathrm{~min}$. Trichloroacetic acid $(0.7 \mathrm{ml}$ of a $100 \%$ solution) was added to the $0.7 \mathrm{ml}$ supernatant. The mixture was allowed to incubate at $14^{\circ} \mathrm{C}$ for $18 \mathrm{~h}$ and then centrifuged again at $1000 \mathrm{~g}$ for $30 \mathrm{~min}$. The amount of EB in the supernatant was determined spectrophotometrically at $610 \mathrm{~nm}$ by comparison against readings obtained from standard solutions (Gursoy-ozdemir et al. 2000).

\subsubsection{Estimation of myeloperoxidase activity}

The myeloperoxidase enzyme was extracted and its activity was measured using a method described by Bradley et al. Briefly, plasma samples were homogenized in $50 \mathrm{mmol} / \mathrm{l}$ potassium phosphate buffer, $\mathrm{pH} 6$, containing $0.5 \%$ hexadecyltrimethyl ammonium bromide. The homogenate was freeze-thawed three times and then centrifuged for $20 \mathrm{~min}$ at $11000 \mathrm{~g}$ and $4^{\circ} \mathrm{C}$. The supernatant $(34 \mathrm{ml})$ was mixed with the same phosphate buffer $(986 \mathrm{ml})$ containing $0.167 \mathrm{mg} / \mathrm{ml}$ ortho-dianisidine dihydrochloride and $0.0005 \%$ hydrogen peroxide. The change in absorbance at $460 \mathrm{~nm}$ was recorded using a spectrophotometer. One unit of MPO activity was defined as that consuming $1 \mathrm{nmol}$ peroxide/min at $22^{\circ} \mathrm{C}$. Results were expressed as unit/mg of tissue protein (Bradley et al. 1982). 


\subsection{Tissue and plasma distribution study}

Animals (Wistar rats 200-250g) were divided into three different groups containing 12 rats in each group and administered with respective treatment. PG (8 mg/kg, i.p) treated group; NOS (10 mg/kg PO) treated group; and combination treated PG $(8 \mathrm{mg} / \mathrm{kg})+$ NOS $(10 \mathrm{mg} / \mathrm{kg})$ groups, 7 days pre-treatment and on the day after surgery (8th day). The blood sample was collected at different time points from the time of administration as $0,0.5,1,2,4,8,16,24,48$, and $72 \mathrm{~h}$. For drug distribution study in the brain after $24 \mathrm{~h}$ of reperfusion, rats were sacrificed and the brain was collected for further analysis. The levels of drugs in rat plasma and brain were analyzed using HPLC (Singh and Pai 2013; Xu et al. 2014). Pharmacokinetics parameter evaluation of PG and NOS including Cmax, Tmax, $\mathrm{t}_{1 / 2}$, and $\mathrm{AUC}_{0-\mathrm{t}}$ were calculated by noncompartmental analysis using the excel add-in PK Solver (Version 2.0) (Zhang et al. 2010) (Fig. 1).

\subsubsection{Simultaneous RP-HPLC bio-analytical method development}

A series of the trail has been done to obtain good peak shape and resolution between analytes at Agilent 1260 HPLC system consist of the analytical column Kromasil C8 $(150 \star 4.6 \mathrm{~mm}, 5 \mathrm{um})$. HPLC grade methanol, acetonitrile, and water were used as mobile phase and diluent at different ratios. The elute was monitored through UV based detector set at 241nm (Karlsson et al. 1990; Zhang et al. 2004; Aneja et al. 2007; Liu et al. 2008; Yan et al. 2014).

\subsubsection{Plasma/brain sample preparation}

Plasma samples were obtained after centrifugation of blood samples at $10,000 \mathrm{rpm} ; 2-4^{\circ} \mathrm{C}$ and supernatant was collected. To $100 \mu \mathrm{l}$ of rat plasma collected at each study point, $300 \mu \mathrm{l}$ of methanol was added and centrifuged at $10000 \mathrm{rpm} ; 2-4^{\circ} \mathrm{C}$ for $10 \mathrm{~min}$. The supernatant was collected and stored at $-20^{\circ} \mathrm{C}$ for HPLC analysis.

The brain tissue was homogenated with isotonic buffer solution $(\mathrm{pH} 7.4)$ and centrifuge at $10,000 \mathrm{rpm} 2-$ $4^{\circ} \mathrm{C}$, the supernatant was collected in an Eppendorf tube. $100 \mu \mathrm{l}$ of brain homogenate was mixed with $300 \mu \mathrm{l}$ of methanol and further centrifuged at $10,000 \mathrm{rpm} ; 2-4^{\circ} \mathrm{C}$, the supernatant was collected and stored in $-20^{\circ} \mathrm{C}$ for HPLC analysis (Wang et al. 2011; Feng et al. 2017; Liao et al. 2018).

\subsubsection{Standard and quality control sample preparation:}

Noscapine and Progesterone standard solution was prepared in HPLC grade methanol similarly a combination of both drug and a quality control sample was also prepared in HPLC grade methanol. Appropriate dilutions of the standard were prepared in HPLC grade methanol to produce $2,4,6,8$, and, 10 $\mu \mathrm{g} / \mathrm{ml}$.

Plasma and brain homogenate calibration samples and were prepared by spiking $100 \mu \mathrm{l}$ of standard solution with $100 \mu \mathrm{l}$ of rat plasma and $100 \mu \mathrm{l}$ of brain homogenate respectively. This mixture was further vortexed for 2 min and $300 \mu \mathrm{l}$ of methanol was added in this mixture and vortexed for 2 min and finally centrifuged at $10000 \mathrm{rpm}$ for $10 \mathrm{~min}$ under cold conditions. The supernatant was collected and injected 
into HPLC. Samples for the determination of recovery, precision, and accuracy were prepared by spiking control rat plasma and brain homogenate in at appropriate concentrations and were stored at $-80^{\circ} \mathrm{C}$ until analysis (Karlsson et al.1990; Zhang et al. 2004; Aneja et al. 2007). Bioanalytical method validation parameters were also performed (Supplemental Data-II).

\subsection{Histological examination}

The rat was decapitated; the brain was rapidly dissected out, washed immediately with saline, and fixed in $10 \%$ buffered formalin. Cerebral hemispheres were embedded in paraffin and sections were cut and stained using hematoxylin and eosin to observe under a microscope for histological change (Margaritescu et al. 2009).

\subsection{Statistical analysis}

The results were calculated as mean \pm standard error of the mean (SEM); the analysis of variance (ANOVA) was applied to calculate the statistical difference. The changes in the oxidative biomarker infarct area and vascular permeability were compared with the sham-operated group by using one-way ANOVA followed by Tukey's test. The data were presented as mean \pm SEM; $p<0.05$ was considered for statistical significance using Prism GraphPad software (GraphPad Software, San Diego, CA, 409 USA).

\section{Results}

\subsection{Effect on cerebral infarct}

Quantitative comparisons of total cerebral infarction volumes have been shown in (Fig. 2a). The rats in the sham group had no cerebral infarction. The total cerebral infarct volume of treatment group PG $\left(40.94 \pm 1.00 \mathrm{~mm}^{3}\right)$, NOS $\left(36.92 \pm 2.30 \mathrm{~mm}^{3}\right)$, and PG+NOS $\left(30.02 \pm 0.52 \mathrm{~mm}^{3}\right)$ was significantly lower than I-R group $\left(73.10 \pm 2.28 \mathrm{~mm}^{3}\right)$. However, all of the treatment groups could reduce the size of infarction especially when the rats were treated with the combination of PG+NOS $\left(30.02 \pm 0.52 \mathrm{~mm}^{3}\right)$ (Fig. 3) (Supplemental Data-I).

\subsection{Reduction in brain edema}

Swelling of the brain was caused by ischemic edema as shown in (Fig. 2b). The volume of the brain in the I-R group ( $84.49 \pm 1.84 \%$ ) was significantly higher in comparison with the treatment groups. Treatment with PG $(71.67 \pm 2.26 \%)$ and NOS alone $(71.99 \pm 1.90 \%)$ showed reduced swelling and the combination treatment with PG+NOS further reduced the brain swelling volume. $(60.74 \pm 1.13 \%)$. The difference in the groups for brain water content was significantly different between the groups (Supplemental Data-I).

\subsection{Improved grip strength}


Grip strength performance in the rotarod test was impaired after reperfusion injury in the animals. Pretreatment for seven days of $P G$ and NOS significantly improved muscle grip strength performance as compared with the I-R $(30.33 \pm 4.00 \mathrm{sec})$ group of rats with the increase in falling latency $(71.00 \pm 2.63$ sec and $69.00 \pm 1.77 \mathrm{sec}$ respectively). The combination of PG and NOS had further increased the latency of the fall in treated and animals, which was better than individual treatment groups. The increase in falling latency $(89.17 \pm 4.45 \mathrm{sec})$ indicated a significant $(p<0.05)$ improvement in grip strength of the treated rats as compared with the I-R group of rats (Fig. 2c) (Supplemental Data-I).

\subsection{Morris water maze: Treatment limits memory deficit}

We used MWM to investigate spatial learning and memory. We examined the performance of each rat for 3 days in the hidden-platform test of MWM. As shown in Fig. 4 the escape latency in the I-R group significantly increased compared with the sham group by day 3 . Interestingly, the escape latency of the PG and NOS group was significantly $(p<0.05)$ lesser than that of I-R rats by day 3 . After 3 days of training, the probe trial was performed on the fourth day, as indicated by the number of crossing and the percentage of total time spent in the previous platform location the sham group rats showed a preference for the target quadrant, reflecting the development of reference memory. As shown in (Fig.5 a, b) the I-R group exhibited an obvious reduction in the target crossing numbers and the percentage of total time spent in the target quadrant compared with the sham group $(p<0.05)$. Pretreatment with PG and NOS in comparison to the I-R group significantly improved these two parameters and increased the preference for the target quadrant (Fig. 5a, b) $(p<0.05)$. Therefore, PG and NOS pre-treatment attenuate spatial learning and memory damage after I-R injury, and the best improvement was observed in the combination group (Supplemental Data-I).

\subsection{Open Field: Improved motor coordination}

The reduction in motor activities \{ambulation, rearing, \& grooming\} and increase in freezing time of the rats in the I-R group were significantly $(p \otimes 0.05)$ higher as compared with the sham group, suggesting anxiety-like effects due to ischemia in rats. Pretreatment of rats with the PG+NOS group showed a significant increase in the motor activity demonstrated by the increased number of line crossing, grooming ( $p \otimes 0.05)$, and decrease in the period of immobility as compared with the I-R group (Fig. 6 a, b, c, d) (Supplemental Data-I).

\subsection{Progesterone and noscapine alleviated oxidative injury}

Challenging the animals with 30 min of BCCAO followed by $24 \mathrm{~h}$ of reperfusion caused oxidative damage as indicated by increased lipid peroxidation, decreased superoxide dismutase activity, and reduction in glutathione levels in the brain as compared with sham treated rats. Seven days of pretreatment with PG and NOS alone had significantly restored depleted superoxide dismutase (4.93 $\pm 0.35 \mathrm{IU}$ vs $7.53 \pm 0.42 \mathrm{IU}$ and $8.04 \pm 0.21 \mathrm{IU}$ respectively) activity and glutathione levels $(4.47 \pm 0.19 \mu \mathrm{g}$ vs $10.29 \pm 0.48 \mu \mathrm{g}$ and $12.41 \pm 0.43 \mu \mathrm{g}$ respectively). It also restricted the elevation in lipid peroxidation $(11.45 \pm 0.25 \mathrm{nmol}$ vs $5.25 \pm 0.36 \mathrm{nmol}$ and $3.47 \pm 0.33 \mathrm{nmol}$ respectively) in the brain, as compared with the control group. 
Furthermore, the combination treatment with PG and NOS significantly $(p<0.05)$ enhanced the scavenging activity of SOD ( $4.93 \pm 0.35 \mathrm{IU}$ vs $9.05 \pm 0.05 \mathrm{IU})$, restored the levels of GSH $(4.47 \pm 0.19 \mu \mathrm{g}$ vs $13.27 \pm 0.29 \mu \mathrm{g})$, and attenuated lipid peroxidation $(11.45 \pm 0.25 \mathrm{nmol}$ vs $2.60 \pm 0.31 \mathrm{nmol})$ in the brain (Fig. 7 a, b, c) (Supplemental Data-I).

\subsection{Reduced BBB dysfunction}

The permeation of EB across BBB was considered as an index to measure the change in vascular permeability in the brain. PG and NOS treated groups showed potent neuroprotective effects by preserving the integrity of the BBB as compared with the control group. The extravasation of EB was significantly $(p<0.05)$ higher in the I-R group as compared with sham, PG, NOS, and the combination treated groups (Fig. 2d) (Supplemental Data-I).

\subsection{Treatment reduced the MPO Activity}

The activity of MPO was used as an indicator of brain inflammation. MPO activity more in the I-R group ( $0.38 \pm 0.007$ units $/ \mathrm{mg}$ protein) compared with the sham group ( $(0.17 \pm 0.01$ units/mg protein). This ischemia[1]induced increase in MPO activity was reduced in the ischemic group that was treated with PG (0.30 \pm 0.01 units/mg protein), NOS ( $0.27 \pm 0.01$ units $/ \mathrm{mg}$ protein), and PG+NOS $(0.24 \pm 0.01 \mathrm{units} / \mathrm{mg}$ protein). The significant difference $(p<0.05)$ brought in combination treatment in comparison with the I-R group, indicated reduced inflammation (Fig. 7d) (Supplemental Data-I).

\subsection{Pharmacokinetic study}

After series of trials, we have found good resolution and peak shape of analytes at Kromasil C8 $(150 * 4.6 \mathrm{~mm}, 5 \mathrm{um})$ column, with the binary mode of methanol and water at a ratio of 50:50. The NOS and PG were detected at $241 \mathrm{~nm}$ and retention time was found to be 7.97 and $10.61 \mathrm{~min}$ respectively. The representative chromatograms for plasma samples and brain samples originating from the pharmacokinetic study in the rat are shown in (Fig. 8 a, b, c, d); the results of bioanalytical method validation parameters are enclosed as supplementary data (Supplemental Data-II and III).

The validated method was then successfully applied to simultaneously quantitate the concentrations of PG and NOS in rat plasma and brain homogenate. The pharmacokinetic (PK) parameters like Cmax, Tmax, half-life, and $\mathrm{AUC}_{0-t}$ were estimated by a non-compartmental analysis using PK solver add-in provided in Microsoft Excel. As shown in Fig. 9 a, b and Table 1, Cmax of PG and NOS increased significantly in combination treatment as compared with individual treatment i.e., $P G(10.11 \pm 0.66 \mu \mathrm{g} / \mathrm{ml}$ vs $6.50 \pm 0.24 \mu \mathrm{g} / \mathrm{ml})$ and NOS $(6.10 \pm 0.97 \mu \mathrm{g} / \mathrm{ml}$ vs $2.35 \pm 0.26 \mu \mathrm{g} / \mathrm{ml})$, at the Tmax for PG and NOS was $0.5 \pm 0.00 \mathrm{~h}$ and $0.66 \pm 0.11 \mathrm{~h}$ in individual treatment and combination $0.5 \pm 0.00 \mathrm{~h}$ and $2 \pm 0.00 \mathrm{~h}$ respectively. Half-life $\left(t_{1 / 2}\right)$ was elongated in combination groups as compared to individual groups but the change was not significant. Meanwhile, the AUC in the combination group was also increased with both the drugs as compared (Table 1), with an individual group and significant difference shown in the AUC of NOS $(74.79 \pm 13.74 \mu \mathrm{g} / \mathrm{ml} * \mathrm{~h}$ vs $27.84 \pm 3.14 \mu \mathrm{g} / \mathrm{ml} * \mathrm{~h})$. Fig. 10 shows the concentration in the 
brain was also significantly increased after combination treatment (at $24 \mathrm{~h}$ ) as compared to individual administration of the drug i.e., PG $(14.53 \pm 0.32 \mu \mathrm{g} / \mathrm{ml}$ vs $12.15 \pm 0.59 \mu \mathrm{g} / \mathrm{ml})$, NOS $(8.03 \pm 0.19 \mu \mathrm{g} / \mathrm{ml}$ vs $5.80 \pm 0.54 \mu \mathrm{g} / \mathrm{ml})$; further investigation at $72 \mathrm{~h}$ none of the drugs was detected in the brain (Supplemental Data-II and Data-III).

\subsection{Histopathological examination}

The histological outcome demonstrated neuronal swelling, dilated blood vessels with neuronal damage, pyknotic nuclei, and shrinkage of nucleus following reperfusion injury. Swelling of vacuolations, disruption of the cell membrane, and increase in intracellular space were observed in the I-R control group of rats (Fig. 11b). While Histopathological observations of the brain slices from rats in the sham group showed intact, neuronal cell structure with the continuous cell membrane (Fig. 11a). PG (Fig. 11c) and NOS (Fig. 11d) reduced disruption of cell membrane but had little effect on vacuolations. However, PG and NOS in combination (Fig. 11e) pretreatment improved cell structure indicated by intact cell membrane and reduced neuronal damage.

\section{Discussion}

The objective of this study was to investigate the outcomes of the pre-treatment schedule with a combination of two pharmacological agents (PG and NOS) on reperfusion injury induced brain damage in rats. We evaluated the effect of PG and NOS on 1) Oxidative stress and behavioral deficit, 2) muscle strength, 3) vascular permeability (BBB damage), 4) inflammatory reactivity, 5) infarct volume. To substantiate the findings, we determined the pharmacokinetic profile of individual drugs alone and in combination in plasma and the brain. This study demonstrated that the combination of PG and NOS has beneficial effects on various outcomes of reperfusion injury and the optimum levels of both agents in the brain, immediately after ischemia, were critical to achieving neuroprotection in rats.

Earlier neuroprotective potential of PG, upon intraperitoneal administration of low dose (8 mg/ $\mathrm{kg}$ ), was reported due to its relatively high concentration in the brain within $15 \mathrm{~min}$ of administration which was sustained during an ischemic period (Wong et al. 2012). PG, as a pleiotropic agent, ameliorated cerebral damage by reducing edema formation through the expression of AQP4 (Wang et al. 2013), resorted BBB dysfunction, and attenuated apoptosis (Guo et al. 2006; Ishrat et al. 2009; Ishrat et al. 2010). Similarly, NOS, a bradykinin receptor antagonist, exhibited marked free radical scavenging ability and inhibition of inflammation in ischemia reperfusion injury (Mahmoudian et al. 2015; Kawadkar et al. 2021). But the correlation of pharmacokinetic profile of both (PG and NOS) with their observed neuroprotective, alone or in combination, effects was missing. We report a unique aspect of combination therapy by simultaneously estimating the levels of PG and NOS in the brain as well as in plasma after pre and post administration in ischemic reperfusion injury.

The combination of PG with NOS has had better behavioral outcomes than that of individual administration of PG and NOS on functional tests like Morris water maze and open field investigations. The decrease in infarct volume and reduced neuronal cell damage in the hippocampal and frontal cortex 
is linked with cognitive and behavioral deficits (Yousouf et al. 2014). Behavioral examination showed a significant improvement in memory and locomotor activity. The decreased latency to find the hidden platform in treated animals could be attributed to the enhanced effect of the combination treatment to attenuate infarct formation in vital regions of the brain (Gibson and Murphy 2004; Yousouf et al. 2014; Hedayatpour et al. 2018; Qin et al. 2019; Kawadkar et al. 2021). According to our results, the number of crossing and the percentage of time spent in the target quadrant significantly increased in all of the treatment groups as compared with I-R group in the probe trial. Besides inhibiting inflammatory reactivity, PG attenuates infarct volume which may be linked to an increase in neurotrophic factor VEGF in the hippocampal and cortical region (Ishrat et al. 2009; Uysal et al. 2013). Similarly, NOS was reported to suppress inflammation, indicated by MPO activity reduction, and free radical in cerebral reperfusion injury, and contributes to restriction of infarct formation in the cortical region (Khanmoradi et al. 2014; Kawadkar et al. 2021). These two agents, PG and NOS, exert the beneficial effect on improvement in spatial memory through different signaling pathways to reduce cortical infarct in the treated animals.

The pro-inflammatory mediators instigated due to lipid peroxidation triggers brain damage (Kalogeris et al. 2014; Kawabori and Yenari 2015). Infiltrated neutrophils, a result of free radical generation, contribute to the release of myeloperoxidase in the endothelium (Bradley et al. 1982). We report inhibition of myeloperoxidase activity by PG and NOS treatment (Fig 7d); it regulates cerebral inflammation and restores the blood-brain barrier (BBB) after reperfusion injury (Ding-Zhou et al. 2003; Ishrat et al. 2009).

Cytokine action on BBB dysfunction gets augmented by neutrophil infiltration; the passive diffusion of water through disorganized BBB swells the brain and increases the volume (Ishrat et al. 2009; Elali et al. 2011; Kawabori and Yenari 2015). These sequential events following free radical generation and ensuing inflammation in endothelium alters the permeability of the vascular system (Nour et al. 2013). Vascular disorganization disrupts the integrity of BBB and permeates fluid to form edema in the brain (Rosenberg and Yang 2007). Noscapine inhibits both, inflammation and stress, whereas PG downregulates expression of AQ4 to reduce edema and decrease BBB permeability (Ishrat et al. 2010; Khanmoradi et al. 2014; Vahabzadeh et al. 2015, Kawadkar et al. 2021). The results of the current investigation reveal that combine treatment of two potent neuroprotective agents had a significant effect on vascular permeability, inflammation, and oxidative stress biomarkers. The evidence suggests NOS and PG elicit these beneficial effects by targeting different mechanisms, however overlapping activity on some of the underlying mechanisms cannot be ruled out while employing the strategy to simultaneously targeting multiple injury factors Uysal et al. 2013; Hedayatpour et al. 2018; Qin et al. 2019).

The availability of NOS in the brain for an extended period would assist in the binding of NOS to its numerous binding sites in the thalamus (Karlsson et al. 1990). It suggests that NOS has a site-specific effect and its ability to readily cross BBB (Landen et al. 2004) further strengthens its neuroprotective claim in reperfusion injury. The addition of PG has reinforced the recovery process in the post-ischemic milieu (within $72 \mathrm{~h}$ ) owing to its pleiotropic properties as a neuroprotective agent (Roof and stein 1992; Iqbal et al. 2002; Sayeed and Stein, 2009; Ishrat et al. 2010). The correlation between plasma and 
brain levels, observed in simultaneous estimation, substantiated the therapeutic outcomes of the combination treatment of post-ischemic reperfusion injury with NOS and PG.

PG had a very short half-life after intraperitoneal administration and accumulates quickly in the brain owing to its lipophilic nature (Wong et al. 2012). The levels of PG in the brain plummeted as it got metabolized by a 5 a-reductase enzyme in neurons but not before exerting its protective effect during the ischemic period (Frye et al. 1998; Wong et al. 2012). Our study demonstrated that in combination PG levels were significantly higher as compared with individual treated animals for an overall duration of ischemia; it reduced thereafter in the reperfusion period. But the presence of $P G$, in higher concentration during ischemia, would attenuate deleterious effects of ischemia on the brain resulting in apoptosis and BBB destruction (Chen et al. 1999; Cutler et al. 2007; Yousuf et al. 2014). Similarly, plasma levels of PG were noteworthy as they peaked late, after $4 \mathrm{~h}$ of ischemia, and stayed relatively higher as compared to brain levels. The liver and spleen are principal metabolizing organs for PG apart from the brain and delayed release of PG from adipose tissues may explain the higher levels in plasma after few hours of administration (Lobo et al. 2002). In addition to PG, we estimated NOS levels in the brain and plasma during ischemia and reperfusion injury. Although NOS readily crosses BBB its rapid elimination and short half-life limit the ability to sustain its concentration in the brain for long (Landen et al. 2004). The emergence of understanding of multiple binding sites, especially in the thalamus, paved the way for the investigation of NOS for pathological conditions other than its previously known antitussive activity (Karlsson et al. 1990). We report higher concentration in the plasma even after 4-6h of administration, especially in the combination group. It is still not clear what led to such prolong availability of NOS in the plasma but the preferential metabolism of PG in the brain may explain the observed levels of NOS. Moreover, the enhanced half-life of NOS could be the outcome of this accumulation in the brain. However, the lack of data regarding drug concentrations in the brain at every time point corresponding to plasma limits the actual comparison between two vital biological samples. Overcoming this limitation of the present study may provide an exact pattern of bio-distribution of these two potential therapeutic agents.

Besides, $A U C C_{(0-t)}$ was improved when PG and NOS were given in combination as compared with the administration of both the drugs individually, and a significant difference was shown in the noscapine treated group. The area under the plot of a plasma concentration versus time gives better insight into the extent of exposure to a drug and its clearance rate from the body. Integrating it over time rather than looking at individual concentration measurements may provide a more accurate estimate of the overall drug exposure. Such measurements are meaningful to assess the net pharmacologic response to a given dose of the drug (Krzyzanski and Jusko 1998).

The effect of PG on cerebral damage was earlier evaluated with multiples dose levels $(4,8,16$, and 32 $\mathrm{mg} / \mathrm{kg}$ ) following stroke injury (Chen et al. 1999; Sayeed and Stein 2009; Ishrat et al. 2010; the lower dose $(8 \mathrm{mg} / \mathrm{kg}$ ) exhibited best neuroprotection than the higher dose $(32 \mathrm{mg} / \mathrm{kg})$ on various aspects of brain damage after stroke (Chen et al. 1999; Cutler et al. 2007; Yousuf et al. 2014). The rationale for choosing the low dose of $P G$ is associated with the unique inverted U-shaped correlation (hormesis phenomenon) between neuroprotection and dose of PG in animal experimentation (Goss et al. 2003; Yousuf et al. 2014), 
which was also reflected in clinical investigation (Pan et al. 2019). We report improved functional outcomes with PG treatment; the increase in time spent by rats on accelerating rotarod indicates improved balance and cognitive ability. The result is in agreement with earlier findings (Gibson and Murphy 2004; Ishrat et al. 2009).

\section{Conclusion}

In conclusion, we demonstrate an improved therapeutic outcome on behavioral, functional, and cognitive disturbances following reperfusion injury with the combination of NOS and PG in rats; the outcomes were better than those observed after individual treatment of each drug. To maximize the translation of preclinical outcomes of a complex disorder like ischemic-reperfusion injury needs a combination of proven neuroprotective agents targeting multiple delayed secondary injury mechanisms. Both PG and NOS modulate vital mechanisms and may have a complementary effect on some of those when administered simultaneously. This rationale approach of harnessing the therapeutic potential of two promising neuroprotective agents may enhance the likelihood of developing a clinical strategy to intervene in cerebral damage caused by ischemic-reperfusion injury. However, further studies will be required to shed more light on the dose-response profile, duration of the combination treatment, and exploring this promising combination in multiple models of ischemic brain injury to ensure its translation in clinical trials.

\section{Declarations}

\section{Funding}

Not applicable

\section{Conflict of interest}

The authors declare that they have no conflicts of interest.

\section{Availability of data and material}

Supplemental source data generated or analyzed during this study presented in form of Prism and excel files.

\section{Code availability}

Not applicable.

\section{Author contributions}

MK performed the experiments, data analysis and wrote the manuscript. VD and ASM helped with the data analysis and contributed to the correction of the manuscript. NS and RM helped in conducting 
experiments throughout the study. VD supervised the entire project. All authors read and approved the manuscript. The authors declare that all data were generated in-house and that no paper mill was used.

\section{Ethics approval}

All animal procedures were approved by the Institutional Animal Ethics Committee of the VNS Institute of

Pharmacy, Bhopal (Madhya Pradesh, India). (Protocol No. PH/IAEC/2K16/010).

\section{Consent to participate}

Not applicable.

\section{Consent for publication}

All authors gave their consent for the publication of this manuscript.

\section{References}

1. Ali-Ahmed F, Federspiel J, Liang L, Xu H, Sevilis T, Hernandez A, Kosinski A, PrvuBettger J, Smith E E, Bhatt D, Schwamm LH, Fonarow G, Peterson E, Xian Y (2019) Intravenous tissue plasminogen activator in stroke mimics. Circ Cardiovasc Qual Outcomes 12: e005609. https://doi.org/10.1161/circoutcomes.119.005609

2. Almahozi A, Radhi M, Alzayer S, Kamal A (2019) Effects of Memantine in a Mouse Model of Postoperative Cognitive Dysfunction. Behav Sci 9:9-24. https://doi.org/10.3390/bs9030024

3. Aneja R, Dhiman N, Idnani J, Awasthi A, Arora S, Chandra R, Joshi H (2007) Preclinical pharmacokinetics and bioavailability of noscapine, a tubulin-binding anticancer agent. Cancer Chemother Pharmacol 60:831-839. https://doi.org/10.1007/s00280-007-0430-y

4. Arakawa K, Takeyoshi I, Akao Y, Totsuka O, Matsumoto K, Morishita Y (2005) Bradykinin B2 receptor antagonist FR173657 ameliorates small bowel ischemia-reperfusion injury in dogs. Dig Dis Sci 50:27-36. https://doi.org/10.1007/s10620-005-1273-1

5. Bradley PP, Priebat DA, Christensen RD, Rothstein G (1982) Measurement of cutaneous inflammation: estimation of neutrophil content with an enzyme marker. J Invest Dermatol 78:206209. https://doi.org/ 10.1111/1523-1747.ep12506462

6. Chen J, Chopp M, Li Y (1999) Neuroprotective effects of progesterone after transient middle cerebral artery occlusion in rat. J Neurol Sci 171: 24-30. https://doi.org/10.1016/S0022-510X(99)00247-6

7. Chodobski A, Zink BJ, Szmydynger-Chodobska, J (2011) Blood-brain barrier pathophysiology in traumatic brain injury. Transl Stroke Res 2: 492-516. https://doi.org/10.1007/s12975-011-0125-x

8. Coomber B, Gibson CL (2010) Sustained levels of progesterone prior to the onset of cerebral ischemia are not beneficial to female mice. Brain Res 1361: 124132. https://doi.org/10.1016/j.brainres.2010.09.037 
9. Cutler SM, Cekic M, Miller DM, Wali B, VanLandingham JW, Stein DG (2007) Progesterone improves acute recovery after traumatic brain injury in the aged rat. J Neurotrauma 24:14751486. https://doi.org/10.1089/neu.2007.0294

10. Danhof M, de Lange EC, Della Pasqua OE, Ploeger BA, Voskuyl RA (2008) Mechanism-based pharmacokinetic-pharmacodynamic (PK-PD) modeling in translational drug research. Trends pharmacol sci 29: 186-191.https://doi.org/10.1016/j.tips.2008.01.007

11. Derendorf H, Lesko LJ, Chaikin P, Colburn WA, Lee P, Miller R, Powell R, Rhodes G, Stanski D, Venitz J (2000) Pharmacokinetic/pharmacodynamics modeling in drug research and development. J Clin Pharmacol 40:1399-1418. PMID: 11185661

12. Diaz-Arrastia R, Kochanek PM, Bergold P, Kenney K, Marx CE, Grimes CJ, Loh LT, Adam LT, Oskvig D, Curley KC, Salzer W (2014) Pharmacotherapy of traumatic brain injury: state of the science and the road forward: report of the Department of Defense Neurotrauma Pharmacology Workgroup. J. Neurotrauma 31:135-158

13. Ding-Zhou L, Margaill I, Palmier B, Pruneau D, Plotkine M, Marchand-Verrecchia C (2003) LF 16-0687 Ms, a bradykinin B2 receptor antagonist, reduces ischemic brain injury in a murine model of transient focal cerebral ischemia. Br J Pharmacol 139:1539-47. http://doi.org/10.1038/sj.bjp.0705385

14. Elali A, Doeppner TR, Zechariah A, Hermann DM (2011) Increased blood-brain barrier permeability and brain edema after focal cerebral ischemia induced by hyperlipidemia: role of lipid peroxidation and calpain-1/2, matrix metalloproteinase-2/9, and RhoA overactivation. Stroke 42:3238-3244

15. El-Etr M, Rame M, Boucher C, Ghoumari AM, Kumar N, Liere P, Pianos A, Schumacher M, Sitruk-Ware $\mathrm{R}$ (2015) Progesterone and nestorone promote myelin regeneration in chronic demyelinating lesions of corpus callosum and cerebral cortex. Glia 63:104-117. http://doi.org/ 10.1002/glia.22736

16. Feng Q, Xu S, Yu J, Sun S, Yang L (2017) Determination of epimedin B in rat plasma and tissue by LC-MS/MS: Application in pharmacokinetic and tissue distribution studies. J Anal Methods Chem 7194075. https://doi.org/10.1155/2017/7194075

17. Frye CA, Bayon LE, Pursnani N K, Purdy RH (1998) The neurosteroids, progesterone and 3a,5a-THP, enhance sexual motivation, receptivity, and proceptivity in female rats. Brain Res 808: 72-83

18. Gaignard P, Liere P, Therond P, Schumacher M, Slama A, Guennoun R (2017) Role of sex hormones on brain mitochondrial function, with special reference to aging and neurodegenerative diseases. Front Aging Neurosci 9: 406. https://doi.org/ 10.3389/fnagi.2017.0040

19. Gallo JM (2010) Pharmacokinetic/ pharmacodynamic-driven drug development. Mt Sinai J Med 77: 381-388. https://doi.org/10.1002/msj.20193

20. Ghoumari AM, Baulieu EE, Schumacher M (2005) Progesterone increases oligodendroglial cell proliferation in rat cerebellar slice cultures. Neuroscience 135:4758. https://doi.org/10.1016/j.neuroscience.2005.05.023

21. Gibson CL, Murphy SP (2004) Progesterone enhances functional recovery after middle cerebral artery occlusion in male mice. J Cereb Blood Flow Metab 24: 805-

813. https://doi.org/10.1097/01.WCB.0000125365.83980.00 
22. González-Orozco JC, Camacho-Arroyo I (2019) Progesterone Actions During Central Nervous System Development. Front Neurosci 13:503. doi: 10.3389/fnins.2019.00503

23. Goss CW, Hoffman SW, Stein DG (2003) Behavioral effects and anatomic correlates after brain injury: a progesterone dose-response study. Pharmacol Biochem Behav 76: 231-242. ISSN 00913057.https://doi.org/10.1016/j.pbb.2003.07.003

24. Gruenbaum SE, Zlotnik A, Gruenbaum BF, Hersey D, Bilotta F (2016) Pharmacologic Neuroprotection for Functional Outcomes After Traumatic Brain Injury: A Systematic Review of the Clinical Literature. CNS drugs 30: 791-806. https://doi.org/10.1007/s40263-016-0355-2

25. Guennoun R, Zhu X, Frechou M, Gaignard P, Slama A, Liere P, Schumacher M (2019) Steroids in stroke with special reference to progesterone. Cell Mol Neurobiol 39:551-568. https://doi.org/ $10.1007 /$ s10571-018-0627-0

26. Guennoun, R. (2019). Cerebroprotection by progesterone following ischemic stroke: Multiple effects and role of the neural progesterone receptors. J Steroid Biochem Mol Biol 185: $90-$ 102. https://doi.org/10.1016/j.jsbmb.2018.07.014

27. Guo Q, Sayeed, Baronne LM, Hoffman SW, Guennoun R, Stein DG (2006) Progesterone administration modulates AQP4 expression and edema after traumatic brain injury in male rats. Exp Neurol 198:469-478. https://doi.org/10.1016/j.expneurol.2005.12.013

28. Gursoy-ozdemir Y, Bolay H, Saribas O, Dalkara T (2000) Role of endothelial nitric oxide generation and peroxynitrite formation in reperfusion injury after focal cerebral ischemia. Stroke 31:19741981. https://doi.org/10.1161/01.str.31.8.1974

29. Hashimoto N, Takeyoshi I, Tsutsumi H, Sunose Y, Tokumine M, Totsuka O, Ohwada S, Matsumoto K, Morishita $Y(2004)$ Effects of a bradykinin B(2) receptor antagonist on ischemia-reperfusion injury in a canine lung transplantation model. J Heart Lung Transplant 23:606613. https://doi.org/10.1016/S1053-2498(03)00297-3

30. Hedayatpour A, Shiasi M, Famitafreshi H, Abolhassani F, Ebrahimnia P, Mokhtari T, Hassanzaeh G, Karimian M, Nazparvar B, Marefati N, Tarzjani MD (2018) Co-Administration of Progesterone and Melatonin Attenuates Ischemia-Induced Hippocampal Damage in Rats. J Mol Neurosci 66: 251-260. doi: 10.1007/s12031-018-1163-6. Epub 2018 Sep 4. PMID: 30182311.

31. Ishrat T, Sayeed I, Atif F, Stein DG (2009) Effects of progesterone administration on infarct volume and functional deficits following permanent focal cerebral ischemia in rats. Brain Res 1257:94101. https://doi.org/10.1016/j.brainres.2008.12.048

32. Ishrat T, Sayeed I, Atif F, Hua F, Stein DG (2010) Progesterone and allopregnanolone attenuate bloodbrain barrier dysfunction following permanent focal ischemia by regulating the expression of matrix metalloproteinases. Exp Neurol 226:183-190. https://doi.org/10.1016/j.expneurol.2010.08.023

33. Iwasaki Y, Ito S, Suzuki M, Nagahori T, Yamamoto T, Konno H (1989) Forebrain ischemia induced by temporary bilateral common carotid occlusion in normotensive rats. J Neurol Sci 90:155165. https://doi.org/10.1016/0022-510x (89)90098-1 
34. Jiang X, Andjelkovic, A, Zhu, Ling \& Yang, Tuo\& Bennett, Michael \& Chen, Jun \& Keep, Richard \& Shi, Yejie (2017) Blood-brain barrier dysfunction and recovery after ischemic stroke. Prog Neurobiol163164:144-171. https://doi.org/10.1016/j.pneurobio.2017.10.001.

35. Kalogeris T, Bao Y, Korthuis RJ (2014) Mitochondrial reactive oxygen species: A double edged sword in ischemia/reperfusion vs preconditioning. Redox Biol 2:702- 714

36. Karlsson MO, Dahlstrom B, Eckernas SA, Johansson M, Alm AT (1990) Pharmacokinetics of oral noscapine. Eur J Clin Pharmacol 39: 275-279. https://doi.org/10.1007/bf00315110

37. Katan M, Luft A (2018) Global Burden of Stroke. Semin Neurol 38:208-211. https://doi.org/10.1055/s-0038-1649503

38. Kawabori M, Yenari MA (2015) Inflammatory responses in brain ischemia. Curr Med Chem 22:12581277. http://doi.org/10.2174/0929867322666150209154036

39. Kawadkar M, Mandloi AS, Saxena V, Tamadaddi C, Sahi C, Dhote VV (2021) Noscapine alleviates cerebral damage in ischemia-reperfusion injury in rats. Naunyn-Schmiedeberg's Arch Pharmacol 394:669-683. https://doi.org/10.1007/s00210-020-02005-x

40. Khanmoradi M, Ali Mard S, Aboutaleb N, Nobakht M, Mahmoudian M (2014) The protective activity of noscapine on renal ischemia-reperfusion injury in male Wistar rat. Iran J Basic Med Sci 17:244-9. PMID: 24904716; PMCID: PMC4046240

41. Krzyzanski W, Jusko WJ (1998) Integrated functions for four basic models of indirect pharmacodynamic response. J Pharm Sci 87: 67-72. https://doi.org/10.1021/js970168r

42. Landen JW, Hau V, Wang M, Davis T, Ciliax B, Wainer BH, Van Meir EG, Glass JD, Joshi HC, Archer DR (2004) Noscapine crosses the blood-brain barrier and inhibits glioblastoma growth. Clin Cancer Res 10:5187-201. https://doi.org/ 10.1158/1078-0432.CCR-04-0360

43. Li H, Wang J, Wang P, Rao Y, Chen L (2016) Resveratrol reverses the synaptic plasticity deficits in a chronic cerebral hypoperfusion rat model. J Stroke Cerebrovasc Dis 25:122128. https://doi.org/ 10.1016

44. Liang LJ, Yang JM, Jin XC (2016) Cocktail treatment, a promising strategy to treat acute cerebral ischemic stroke. Med Gas Res 6:33-38. https://doi.org/ 10.4103/2045-9912.179343

45. Liao W, Huang X, Yin Y, Liu B, Zhu R (2018) In vivo microdialysis with ultra-performance liquid chromatography-mass spectrometry for analysis of tetramethylpyrazine and its interaction with borneol in rat brain and blood. Biomed Chromatogr 32: e4210. https://doi.org/10.1002/bmc.4210

46. Liu YF, Yang XW, Lu W, Xin XL (2008) Determination and pharmacokinetic study of tussilagone in rat plasma by RP-HPLC method. Biomed Chromatogr 22:1194-200. https://doi.org /10.1002/bmc.1042

47. Lobo RA, Crosignani PG, Paoletti R, Bruschi F (2002) Progestogens: New Approaches Women's Health and Menopause. Medical Science Symposia Series, vol 17. Springer, Boston, MA. https://doi.org/10.1007/978-1-4615-1061-1-20

48. Lowery OH, Rosenbrough NJ, Farr Al, Randall RJ (1951) Protein measurement with the folin phenol reagent. J Biol Chem 193:265 -275. PMID: 14907713 
49. Lu Q, Tucker D, Dong Y, Zhao N, Zhang Q (2016) Neuroprotective and Functional Improvement Effects of Methylene Blue in Global Cerebral Ischemia. Mol Neurobiol 53:53445355. https://doi.org/10.1007/s12035-015-9455-0

50. Mahmoudian M, Rezvani M, Rohani M, Benaissa F, Jalili M, Ghourchian S (2015) A novel effect of Noscapine on patients with massive ischemic stroke: A pseudo-randomized clinical trial. Iran J Neurol 14:12-16. PMID: 25874051

51. Mahmoudian M, Siadatpour Z, Ziai SA, Mehrpour M, Benaissa F, Nobakht M (2003) Reduction of the prenatal hypoxic-ischemic brain edema with noscapine. Acta Physiol Hung 90:313-318. http://doi.org/ 10.1556/aphysiol.90.2003.4.4

52. Margaritescu O, Mogoanta L, Pirici D, Cernea D, Margaritescu C (2009) Histopathological changes in acute ischemic stroke. Romanian J Morphol Embryol 50:327 -339.PMID: 19690757

53. Marklund S, Marklund G (1974) Involvement of the superoxide anion radical in the autooxidation of pyrogallol and a convenient assay for superoxide dismutase. Eur J Biochem 47:469 -474. https://doi.org/ 87910.1111/j.1432-1033.1974.tb03714.x

54. Moron MS, Depierre JW, Mannerwik B (1979) Levels of glutathione, glutathione reductase and glutathione S-transferase activities in rat lung and liver. Biochim Biophys Acta 582:67 -78. https://doi.org/ 89010.1016/0304-4165(79)90289-7

55. Morris RG, Garrud P, Rawlins J N, O'Keefe J (1982) Place navigation impaired in rats with hippocampal lesions. Nature 297: 681-683

56. Moscote-Salazar LR, Narvaez-Rojas A, Agrawal A, Satyarthee GD, Hoz S, Maraby-Salgado J, Joaquim AF (2018) Neuroprotective effects of progesterone in acute brain trauma and its physiological mechanism. J Acute Dis 7:20-25. http://www.jadweb.org/text.asp?2018/7/1/20/228874

57. Nour M, Scalzo F, Liebeskind DS (2013) Ischemia-reperfusion injury in stroke. Interv Neurol 1:185199. http://doi.org / 10.1159/000353125

58. O'Collins VE, Macleod MR, Donnan GA, Horky LL, van der Worp BH, Howells DW (2006) 1,026 experimental treatments in acute stroke. Ann Neurol 59:467-477. https://doi.org/10.1002/ana.20741

59. O'Collins, VE, Macleod MR, Cox S F, Van Raay L, Aleksoska E, Donnan GA, Howells DW (2011) Preclinical drug evaluation for combination therapy in acute stroke using systematic review, metaanalysis, and subsequent experimental testing. J Cereb Blood Flow Metab 31: 962975. https://doi.org/10.1038/jcbfm.2010.184

60. Pan ZY, Zhao Y H, Huang W H, Xiao Z Z, Li ZQ (2019) Effect of progesterone administration on the prognosis of patients with severe traumatic brain injury: a meta-analysis of randomized clinical trials. Drug Des Devel Ther 13: 265-273. https://doi.org/10.2147/DDDT.S192633

61. Pardridge W. M. (2012) Drug transport across the blood-brain barrier. J Cereb Blood Flow Metab 32:1959-1972. https://doi.org/10.1038/jcbfm.2012.126

62. Patil S, Tawari S, Mundhada, D, Nadeem S (2015) Protective effect of berberine, an isoquinoline alkaloid ameliorates ethanol-induced oxidative stress and memory dysfunction in rats. Pharmacol 
Biochem Behav 136: 13-20. https://doi.org/10.1016/j.pbb.2015.07.001

63. Qin A, Zhang Q, Wang J, Sayeed I, Stein DG (2019) Is a combination of progesterone and chloroquine more effective than either alone in the treatment of cerebral ischemic injury?. Restor Neurol Neurosci 37:1-10. https://doi.org/10.3233/RNN-180837

64. Rajsic S, Gothe H, Borba HH, Sroczynski G, Vujicic J, Toell T, Siebert U (2019) Economic burden of stroke: a systematic review on post-stroke care. Eur J Health Econ 20:107-134.https://doi.org/ doi:10.1007/s10198-018-0984-0

65. Rida PC, LiVecche D, Ogden A, Zhou J, Aneja R (2015) The noscapine chronicle: a pharmaco-historic biography of the opiate alkaloid family and its clinical application. Med Res Rev 35:10721096.https://doi.org/10.1002/med.21357

66. Ritter J. M. (2008). Pharmacokinetic(s) matters: stroke treatment et cetera. Br J Clin Pharmacol 65(3), 299-300. https://doi.org/10.1111/j.1365-2125.2008.03152.x

67. Rogers DC, Campbell CA, Jennifer L, Stretton L, Macky KB (1997) Correlation between motor impairment and infarct volume after permanent and transient middle artery occlusion in rat. Stroke 28:2060-2065. https://doi.org/10.1161/01.str.28.10.2060

68. Roof R L, Stein DG (1992) Progesterone treatment attenuates brain edema following contusion injury in male and female rats. Restor Neurol Neurosci 4:425-427. https://doi.org/1010.3233/RNN-19924608

69. Rosenberg GA, Yang Y (2007) Vasogenic edema due to tight junction disruption by matrix metalloproteinases in cerebral ischemia. Neurosurg Focus 15:22(5): E4. https://doi: 10.3171/foc.2007.22.5.5.

70. Sayeed I, Stein DG (2009) Progesterone as a neuroprotective factor in traumatic and ischemic brain injury. Prog Brain Res 175:219-237. https://doi.org/10.1016/S0079-6123(09)17515-5

71. Schwab M, Bauer R, Zwiener U (1997) The distribution of normal brain water content in Wistar rats and its increase due to ischemia. Brain Res 749:82-87. https://doi.org/10.1016/s00068993(96)01165-1

72. Singh G, Pai RS (2013) High-Performance Liquid Chromatographic Method for Analysis of Emtricitabine in Rat Plasma: Method Development, Validation and Application to a Pharmacokinetic Study. Int Sch Res Notices ISRN Article ID 329072.https://doi.org/10.1155/2013/329072

73. Slater TF, Sawyer BC (1971) The stimulatory effects of carbon tetrachloride and other halogenoalkanes or peroxidative reactions in rat liver fractions in vitro. Biochem J 123:805-814. https://doi.org/10. 9331042/bj1230805

74. Souza D G, Pinho V, Pesquero J L, Lomez E S, Poole S, Juliano L, Correa A, Jr de A Castro, M. S, Teixeira M M (2003) Role of the bradykinin B2 receptor for the local and systemic inflammatory response that follows severe reperfusion injury. Br J Pharmacol 139:129139. https://doi.org/10.1038/sj.bjp.0705200

75. Thiyagarajan M, Sharma SS (2004) Neuroprotective effect of curcumin in middle cerebral artery occlusion induced focal cerebral ischemia in rats. Life Sci 74:968- 
985. https://doi.org/10.1016/j.Ifs.2003.06.042

76. Thompson BJ, Ronaldson PT (2014) Drug delivery to the ischemic brain. Adv Pharmacol (San Diego, Calif.) 71:165-202. https://doi.org/10.1016/bs.apha.2014.06.013

77. Tiwari V, Kuhad A, Chopra K (2009) Suppression of neuro-inflammatory signaling cascade by tocotrienol can prevent chronic alcohol induced cognitive dysfunction in rats. Behav. Brain Res 93: 183-189. https://doi.org/10.1016/j.bbr.2009.05.016

78. Tuzcu M, Baydas G (2006) Effect of melatonin and vitamin E on diabetes-induced learning and memory impairment in rats. Eur. J. Pharmacol 537: 106-

110. https://doi.org/10.1016/j.ejphar.2006.03.024

79. Uysal N, Baykara B, Kiray M, Cetin F, Aksu I, Dayi A., Gurpinar T, Ozdemir D, Arda MN (2013) Combined treatment with progesterone and magnesium sulfate positively affects traumatic brain injury in immature rats. Turk Neurosurg 23:129-137. https://doi: 10.5137/1019-5149.jtn.558211.1.

80. Vahabzadeh G, Rahbar-Roshandel N, Ebrahimi SA, Mahmoudian M (2015) Neuroprotective effect of noscapine on cerebral oxygen-glucose deprivation injury. Pharmacol Rep. 67:281-8. http//doi.org /10.1016/j.pharep.2014.10.011.

81. Wang T, Oberoi RK, Elmquist W F (2011) Determination of cediranib in mouse plasma and brain tissue using high-performance liquid chromatography-mass spectrometry. J Chromatogr B Analyt Technol Biomed Life Sci 879: 3812-3817. https://doi.org/10.1016/j.jchromb.2011.10.025

82. Wang W, Liu L, Jiang P, Chen C, Zhang T (22017) Levodopa improves learning and memory ability on global cerebral ischemia-reperfusion injured rats in the Morris water maze test. Neurosci Lett 636:233-240. doi:10.1016/j.neulet.2016.11.026

83. Wang X, Zhang J, Yang Y, Dong W, Wang F, Wang L, Li X (2013) Progesterone attenuates cerebral edema in neonatal rats with hypoxic-ischemic brain damage by inhibiting the expression of matrix metalloproteinase-9 and aquaporin-4. Exp Ther Med 6:263-267. https://doi.org/ 10.3892/etm.2013.1116

84. Wong R, Ray D, Kendall DA (2012) Progesterone pharmacokinetics in the mouse: implications for potential stroke therapy. J Pharm Pharmacol 64:1614-1620. https://doi.org/10.1111/j.20427158.2012.01537.x

85. Xu P, Li Y, Du SY, Lu Y, Bai J, Guo QL (2014) Comparative pharmacokinetics of borneol in cerebral ischemia-reperfusion and sham-operated rats. J Zhejiang Univ Sci B 15: 8491. https://doi.org/10.1631/jzus.B1300141

86. Yan L, Yin P, Ma C, Liu Y (2014) Method development and validation for pharmacokinetic and tissue distributions of ellagic acid using ultrahigh performance liquid chromatography-tandem mass spectrometry (UPLC-MS/MS). Molecules 19:1892318935. https://doi.org/10.3390/molecules191118923

87. Yanpallewar S, Hota D, Rai S, Kumar M, Acharya S (2004) Nimodipine attenuates biochemical, behavioral, and histopathological alterations induced by acute transient and long-term bilateral 
common carotid occlusion in rats. Pharmacol Res 49:143-

150. https://doi.org/10.1016/j.phrs.2003.08.005

88. Yousuf S, Sayeed I, Atif F, Tang H, Wang J, Stein DG (2014) Delayed progesterone treatment reduces brain infarction and improves functional outcomes after ischemic stroke: a time-window study in middle-aged rats. J. Cereb. Blood Flow Metab 34: 297-306. https://doi.org/ 10.1038/jcbfm.2013.198

89. Zhang L, Zhang ZG, Chopp M (2012) The neurovascular unit and combination treatment strategies for stroke. Trends Pharmacol Sci 33:415-422. https://doi.org/ 10.1016/j.tips.2012.04.006

90. Zhang LW, Chao RB (2004) Determination of progesterone and its main metabolite in rat plasma and uterus using HPLC. Acta pharm Sin B 39: 613-617. PMID: 15563063

91. Zhang Y, Huo M, Zhou J, Xie, S (2010) PK Solver: An add-in program for pharmacokinetic and pharmacodynamic data analysis in Microsoft Excel. Comput Methods Programs Biomed 99: 306314. https://doi.org/10.1016/j.cmpb.2010.01.007

92. Zhu X, Frechou M, Liere P, Zhang S, Pianos A, Fernandez N, Guennoun R (2017) A role of endogenous progesterone in stroke cerebroprotection revealed by the neural-specific deletion of its intracellular receptors. J Neurosci 37: 10998-11020. https://doi.org/10.1523/jneurosci.3874-16.2017

\section{Tables}

Table 1

Pharmacokinetic parameters of PG and NOS individual and simultaneous treatment

Parameters Individual treatment Simultaneous treatment

\begin{tabular}{|lllll|}
\hline & PG & NOS & PG & NOS \\
\hline Cmax $(\mu \mathrm{g} / \mathrm{ml})$ & $6.50 \pm 0.24$ & $2.35 \pm 0.26$ & $10.11 \pm 0.66^{\mathrm{a}}$ & $6.10 \pm 0.97^{\mathrm{b}}$ \\
\hline $\operatorname{Tmax}(\mathrm{h})$ & $0.5 \pm 0.00$ & $0.66 \pm 0.11$ & $0.5 \pm 0.00$ & $2.00 \pm 0.00^{\mathrm{a}, \mathrm{b}}$ \\
\hline $\mathrm{t}_{1 / 2}(\mathrm{~h})$ & $12.80 \pm 1.34$ & $13.07 \pm 1.12$ & $16.85 \pm 2.61$ & $19.46 \pm 2.93$ \\
\hline $\begin{array}{l}\text { AUC } 0-\mathrm{t} \\
(\mu \mathrm{g} / \mathrm{ml} \text { *h) }\end{array}$ & $99.10 \pm 4.77^{\mathrm{b}}$ & $27.84 \pm 3.14^{\mathrm{a}}$ & $100.42 \pm 10.41$ & $74.79 \pm 13.74^{\mathrm{a}, \mathrm{b}}$ \\
\hline
\end{tabular}

\section{Figures}



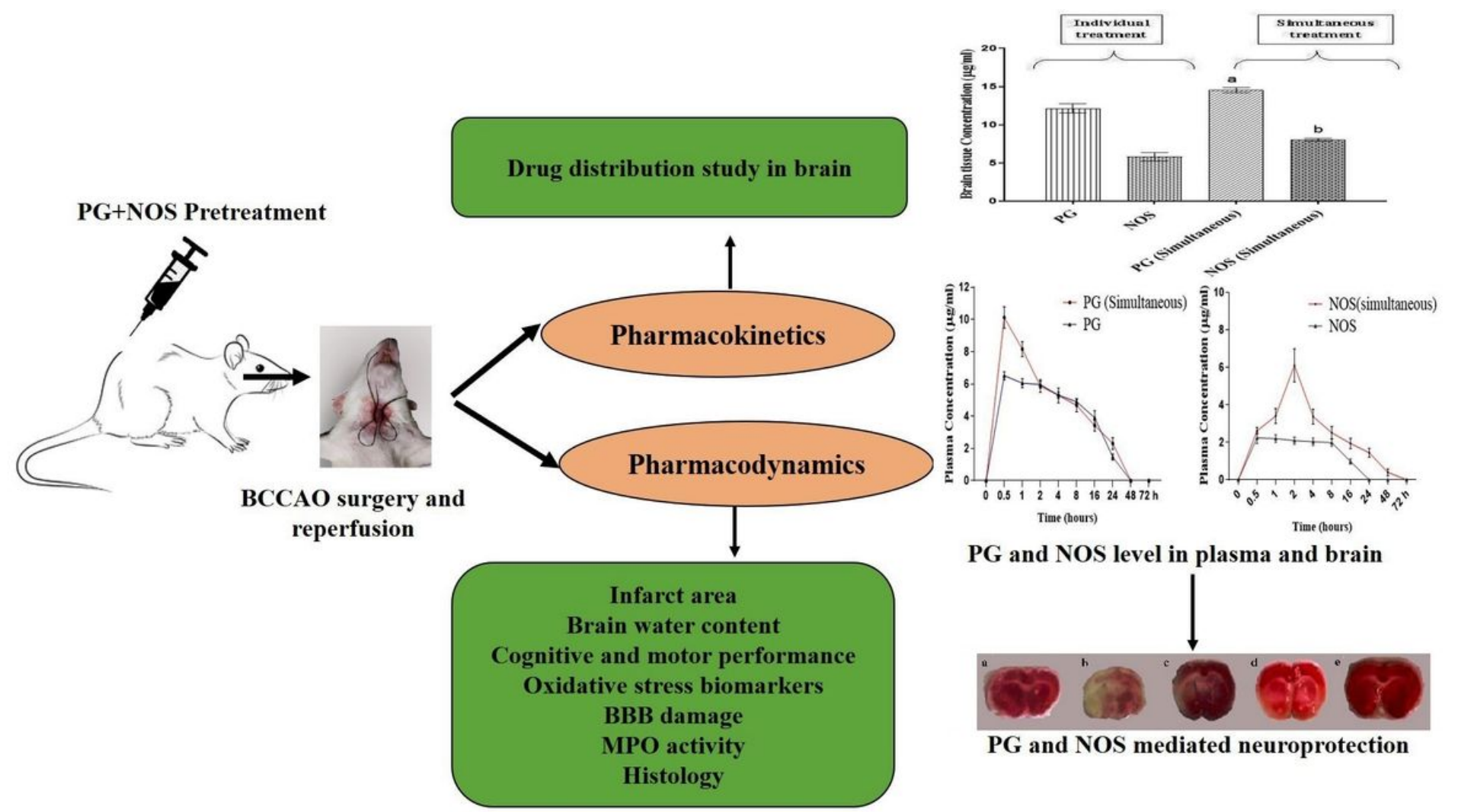

PG and NOS level in plasma and brain

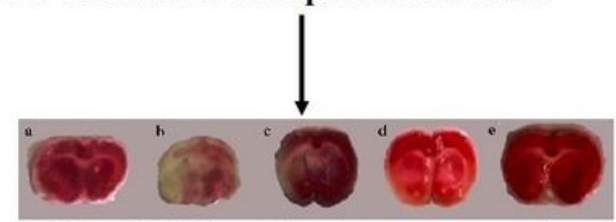

PG and NOS mediated neuroprotection

Figure 1

Graphical abstract for the study 
(a)

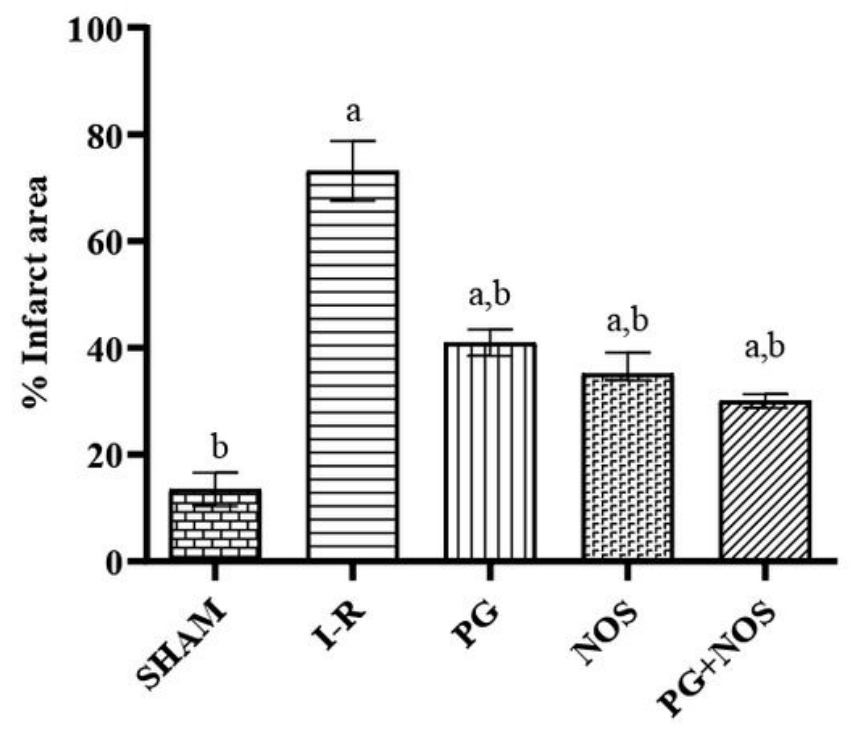

(c)

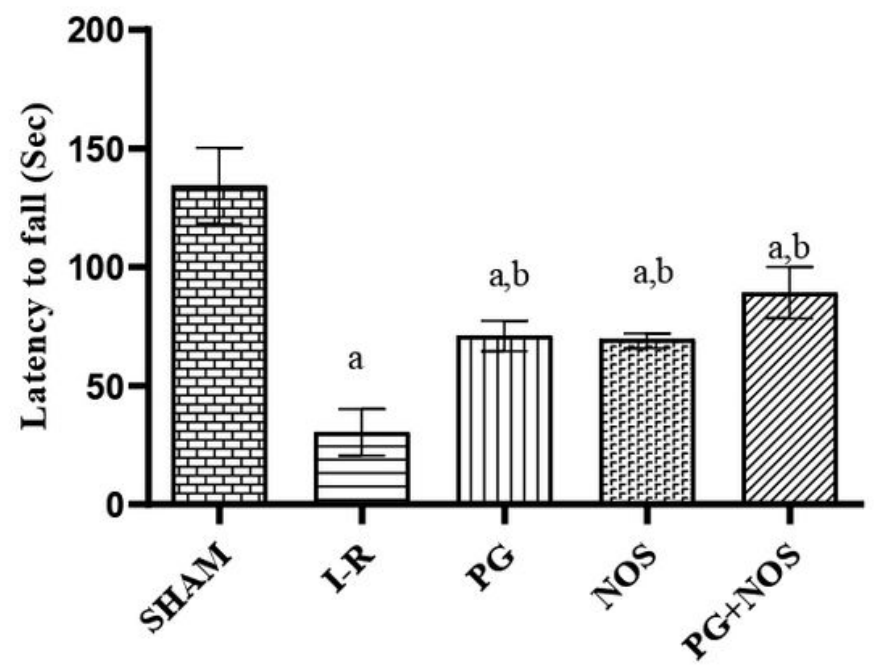

(b)

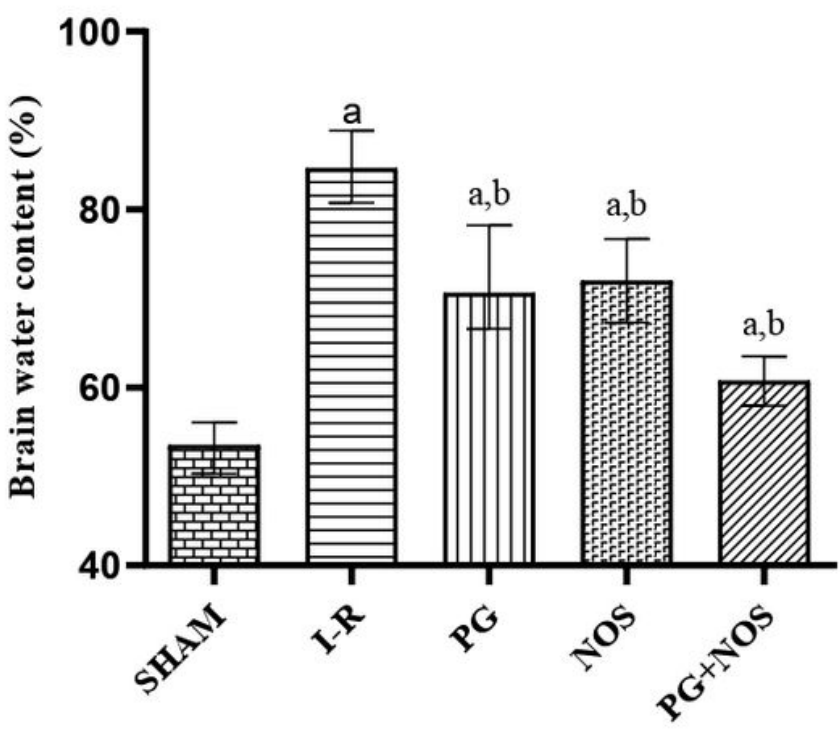

(d)

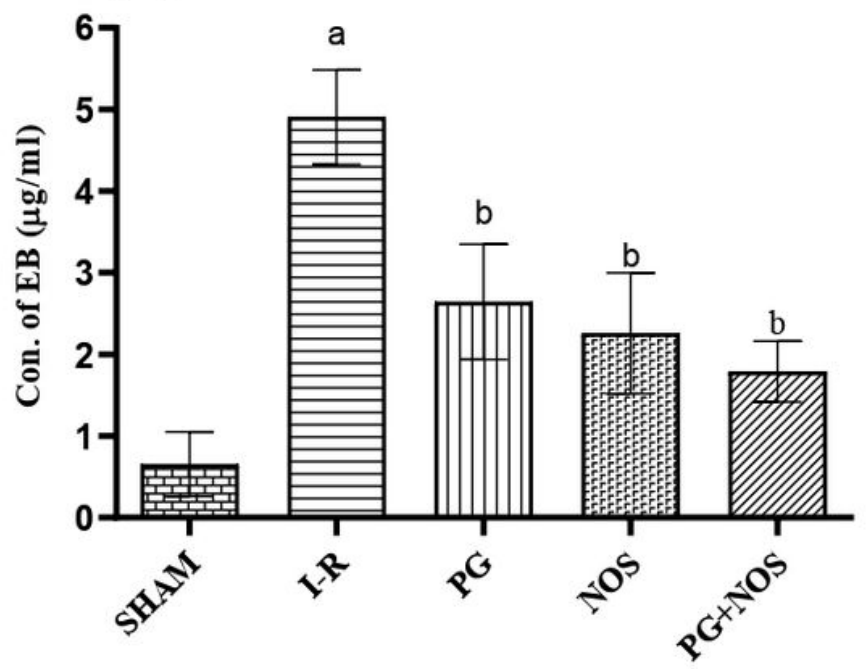

Figure 2

a \% Infarct after 30 min bilateral common carotid cerebral artery occlusion and $24 \mathrm{~h}$ reperfusion in vehicle-treated reperfused PG and NOS-treated rats. b Effect of PG, NOS, and PG+NOS combination on the Brain water content of rat brain. c Effect of PG, NOS, and PG+NOS combination on latency to fall on Rota -Rod. d Outflow of Evans blue extravasations from BBB in the different experimental groups in rat brain. All values represent the mean \pm SEM $(n=6)$. Statistical analysis was carried out by one-way ANOVA followed by Tukey's test. Significant difference from sham- operated group at ap $<0.05$. Significant difference from the I-R group at $b p<0.05$ 


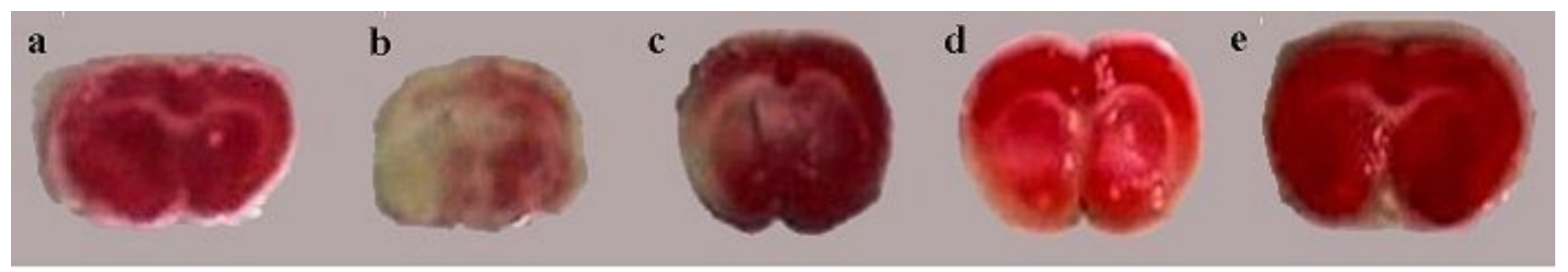

Figure 3

Coronal brain sections $(2 \mathrm{~mm})$, stained with $2 \%$ triphenyl tetrazolium chloride, showing infarction. a Sham group. b I-R group. c PG-8. d NOS-10. e PG+NOS $(8+10 \mathrm{mg} / \mathrm{kg})$. The red area represents the nonischemic area, whereas the pale area indicates ischemic areas in the coronal sections

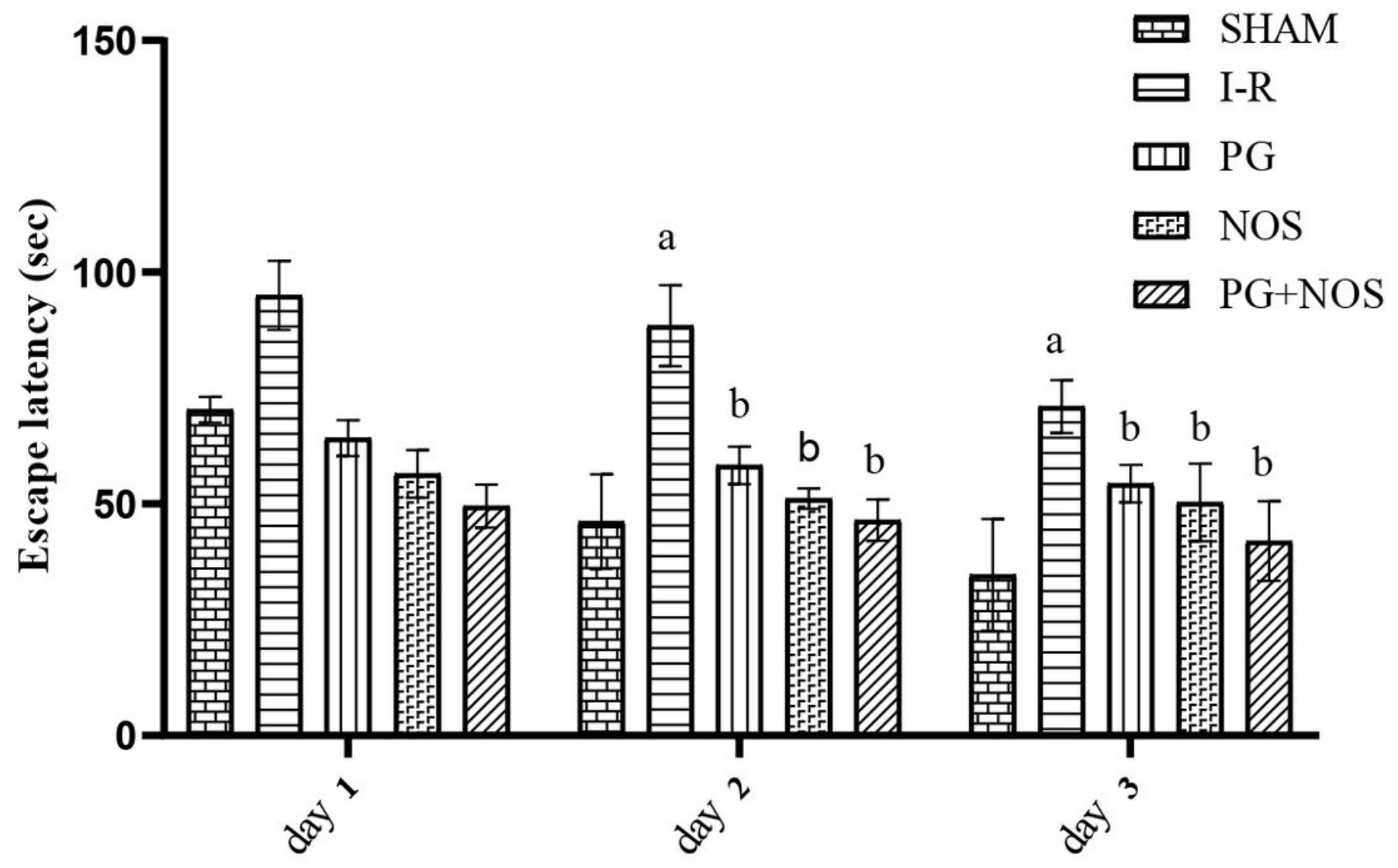

Figure 4

Latency in the Morris water maze test. The time that each rat spent to reach the hidden platform (latency) during the 3 days was recorded and compared. All values represent the mean \pm SEM $(n=6)$. Significant difference from sham- operated group at ap $<0.05$. Significant difference from l-R group at $b p<0.05$ 

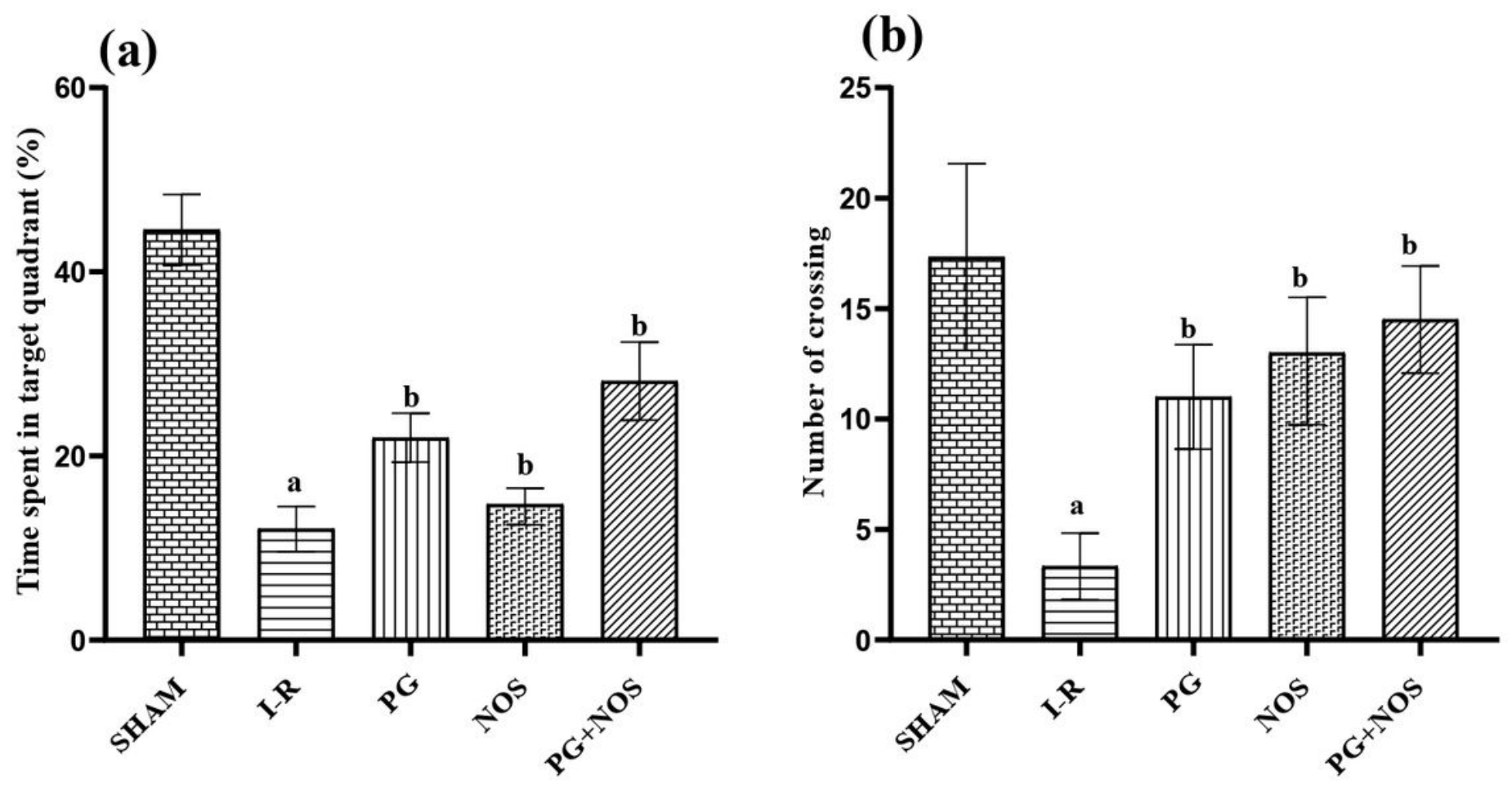

\section{Figure 5}

Behaviors in the Morris water maze without a platform. On the 4th day, the platform was removed for the memory test. a The percentage of time spent in the quadrant where the platform was located was calculated. $b$ The number of that rats crossed the previous platform location in each group was presented. All values represent the mean \pm SEM $(n=6)$. Significant difference from sham- operated group at ap $<0.05$. Significant difference from I-R group at $b p<0.05$ 
(a)

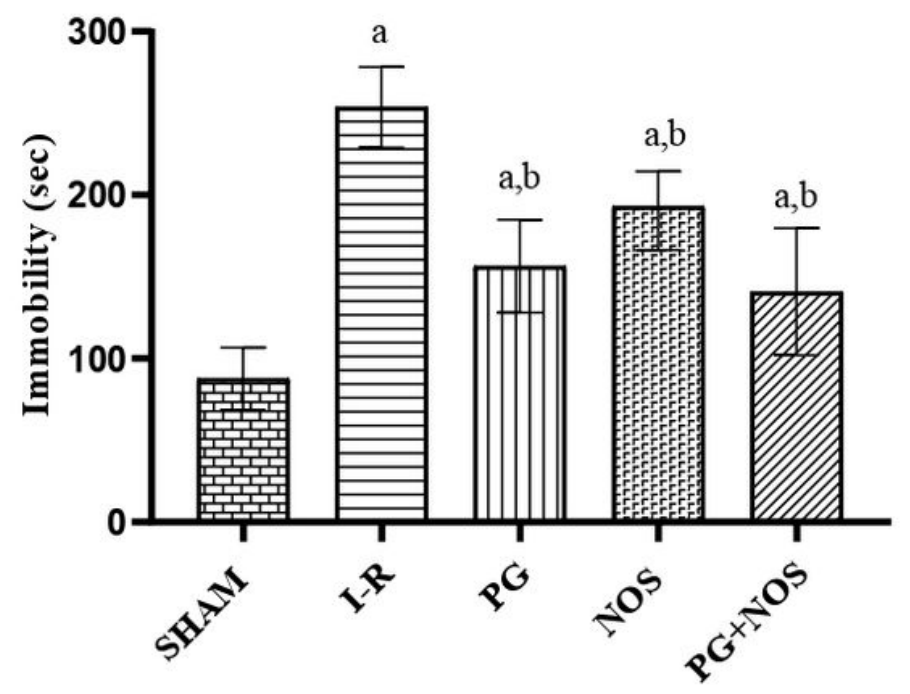

(c)

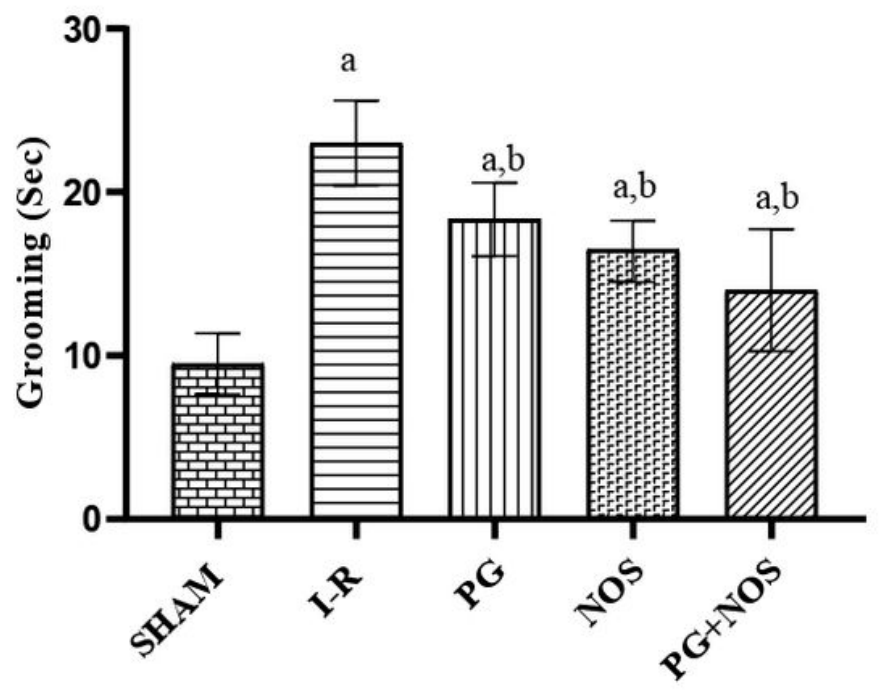

(b)

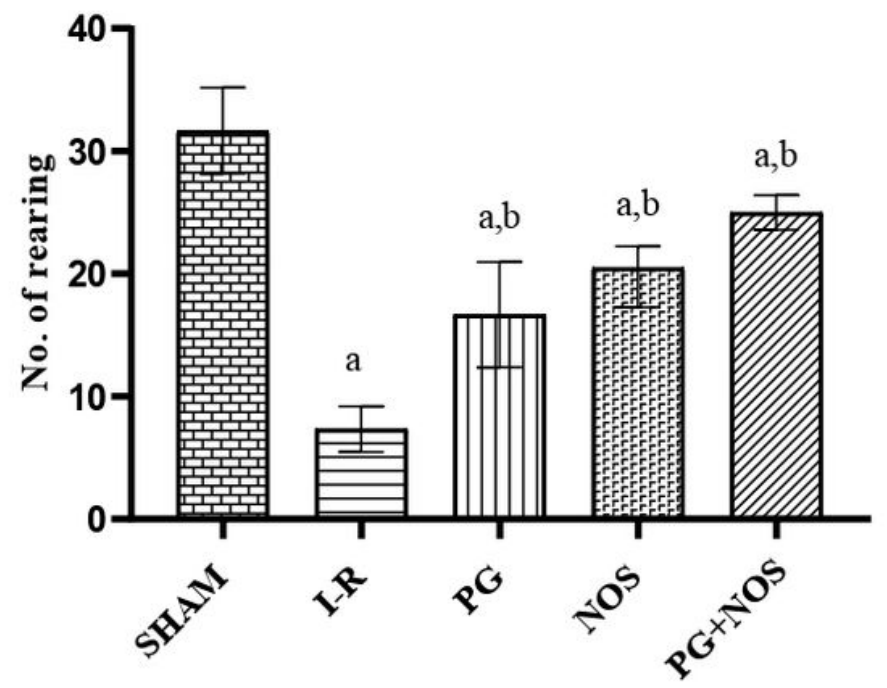

(d)

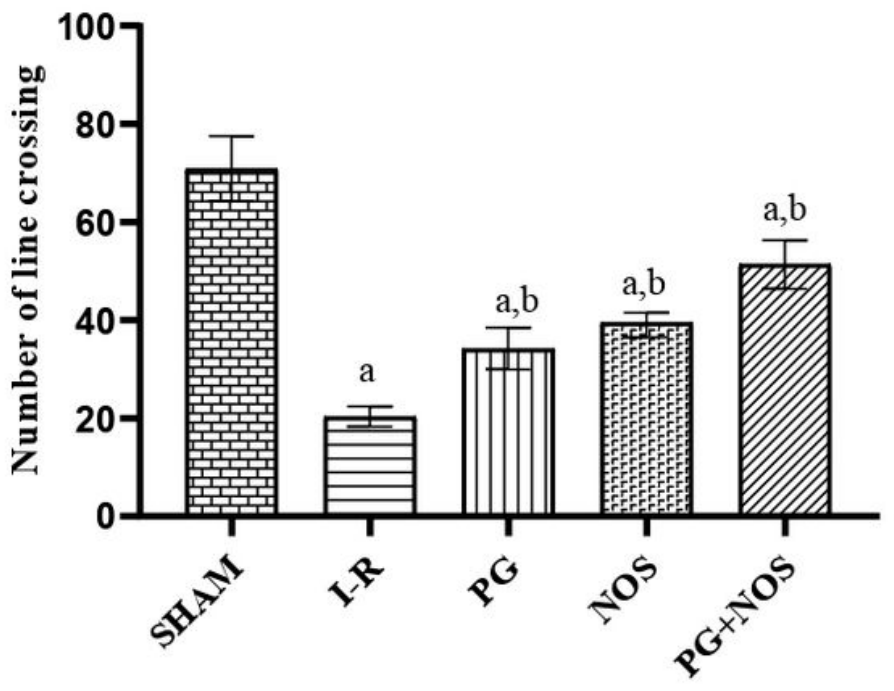

Figure 6

Effects of treatment with PG, NOS, and PG+NOS on the open field activity. a Immobility. b Number of rearing. $c$ Grooming. $d$ Number of line crossing. All values represent the mean \pm SEM $(n=6)$. Significant difference from sham- operated group at ap $<0.05$. Significant difference from I-R group at $b p<0.05$ 

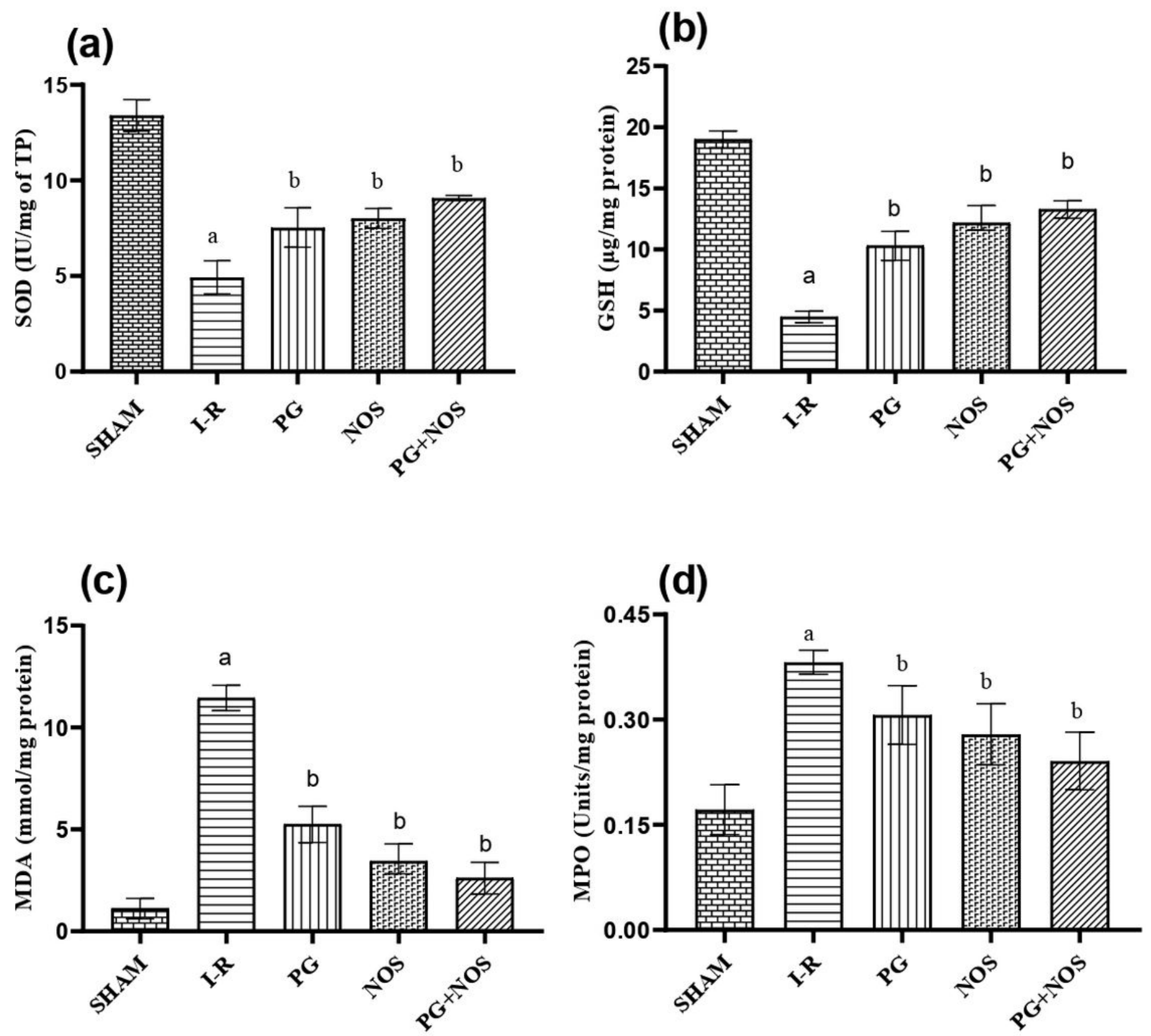

Figure 7

a Effect of PG, NOS, and PG+NOS on superoxide dismutase (SOD) in the brain homogenates of rats. b The effect of PG, NOS, PG+NOS on GSH levels in the brain homogenates of rats. c Effect of PG, NOS, and $P G+N O S$ on brain MDA levels following cerebral ischemia reperfusion. $d$ The effect of PG, NOS, and $\mathrm{PG}+\mathrm{NOS}$ on myeloperoxidase activity in rats following cerebral ischemia reperfusion. All values represent the mean \pm SEM $(n=6)$. Significant difference from sham- operated group at ap $<0.05$. Significant difference from I-R group at $\mathrm{bp}<0.05$ 
(a)

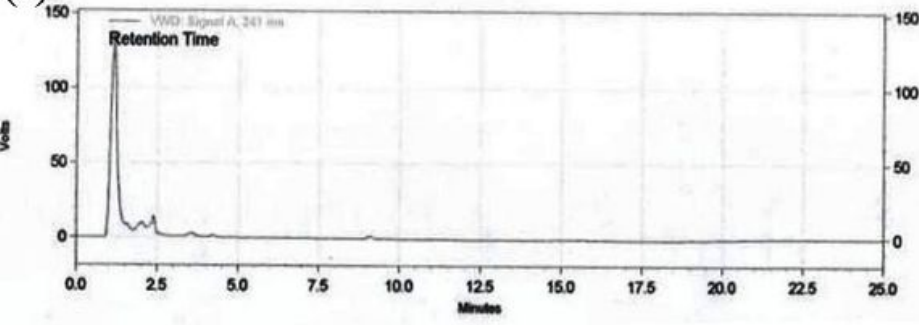

(c)

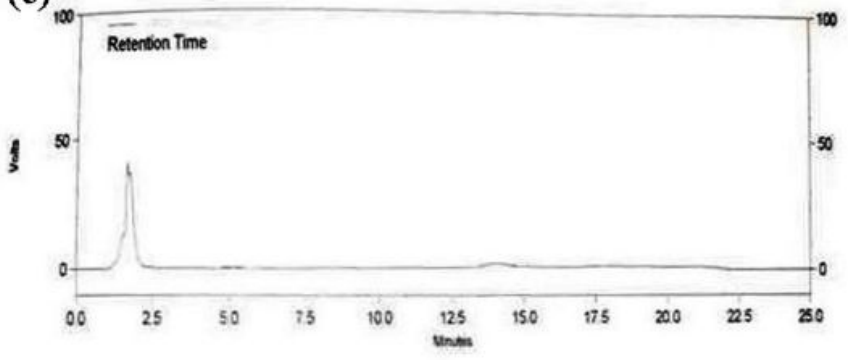

(b)

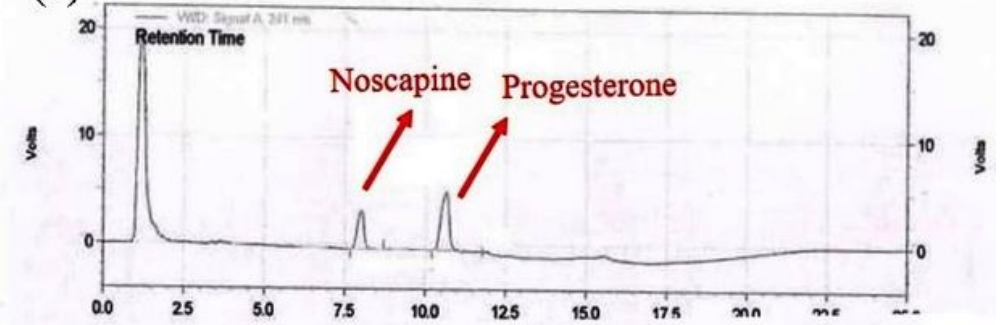

(d)

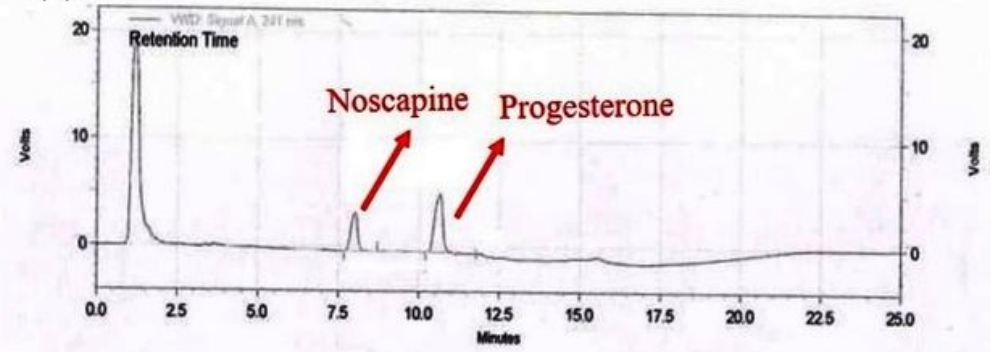

Figure 8

a The representative chromatogram for blank plasma. b The representative chromatogram for noscapine and progesterone spiked in plasma. $c$ The representative chromatogram for blank brain homogenate. $d$ The representative chromatogram for noscapine and progesterone spiked in brain homogenate

(a)

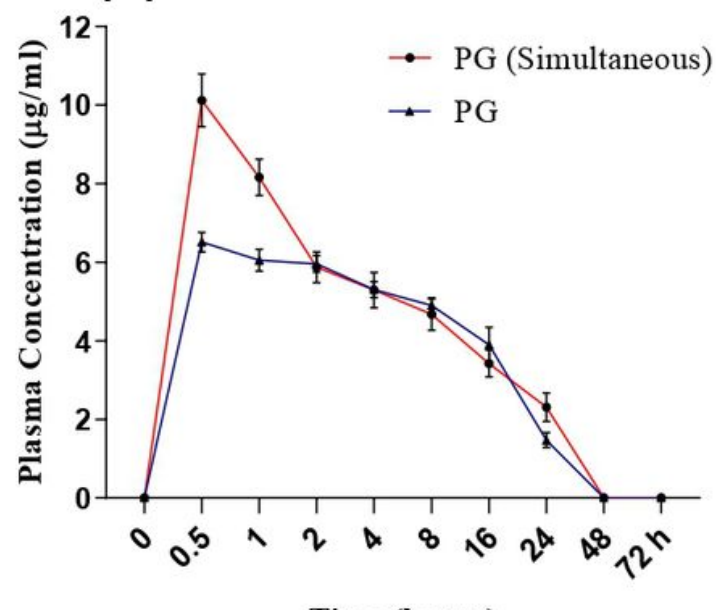

(b)

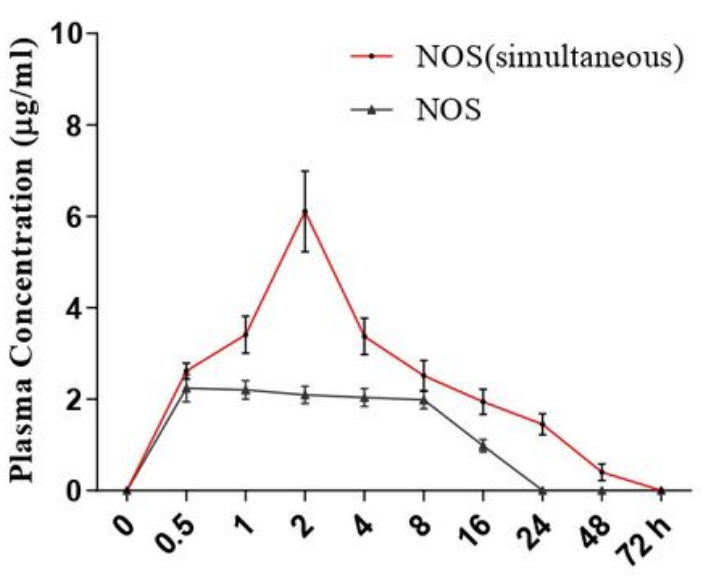

Time (hours)

\section{Figure 9}

Plasma PG and NOS concentration profiles. a Shows the mean plasma concentrations vs. time curve for PG. $b$ shows the mean plasma concentrations vs. time curve for NOS 


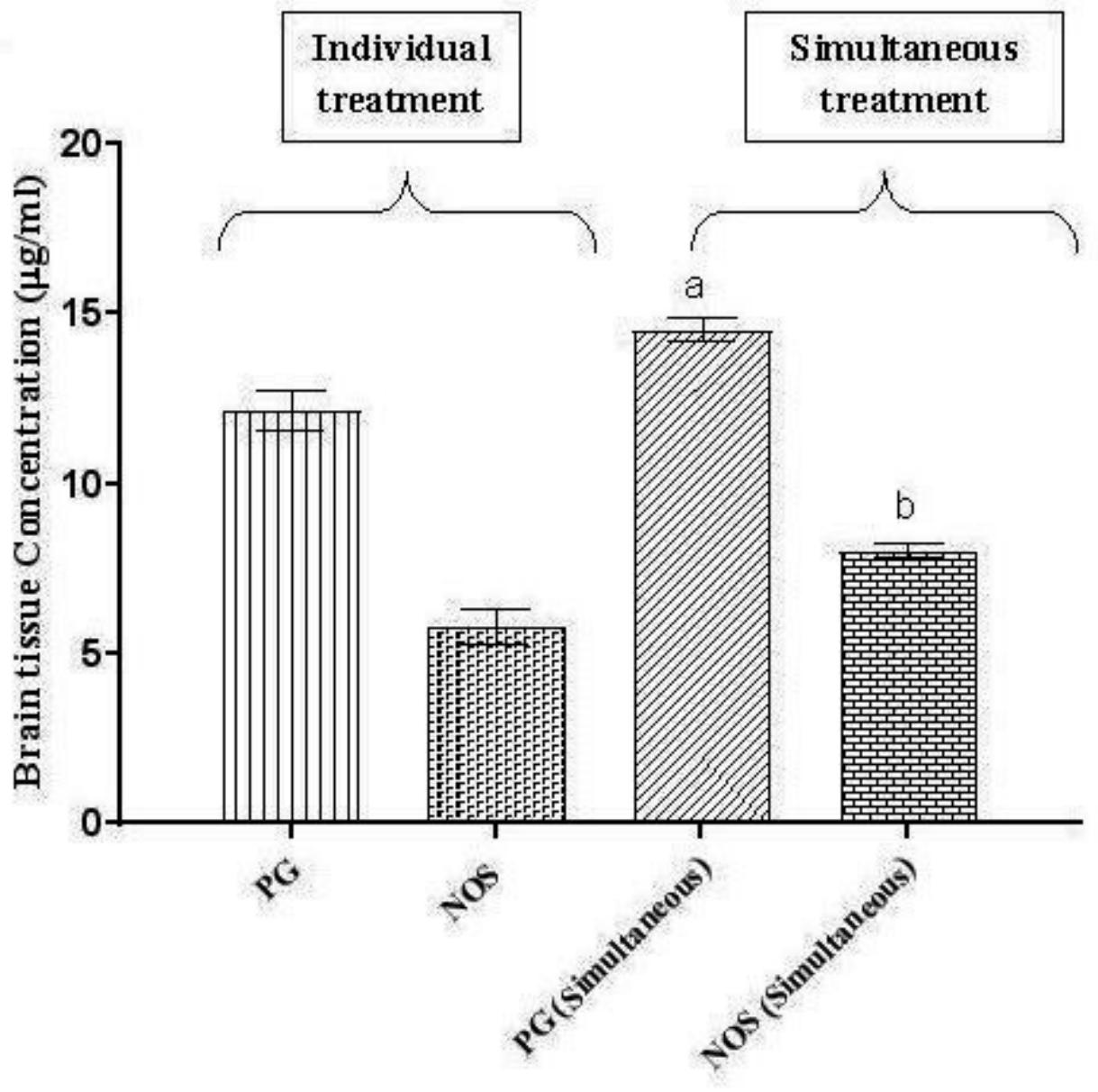

Figure 10

$P G$ and NOS concentration in rat brain. All values represent the mean \pm SEM $(n=6)$. Significant difference from PG individual group at ap $<0.05$. Significant difference from NOS individual group at bp $<$ 0.05 

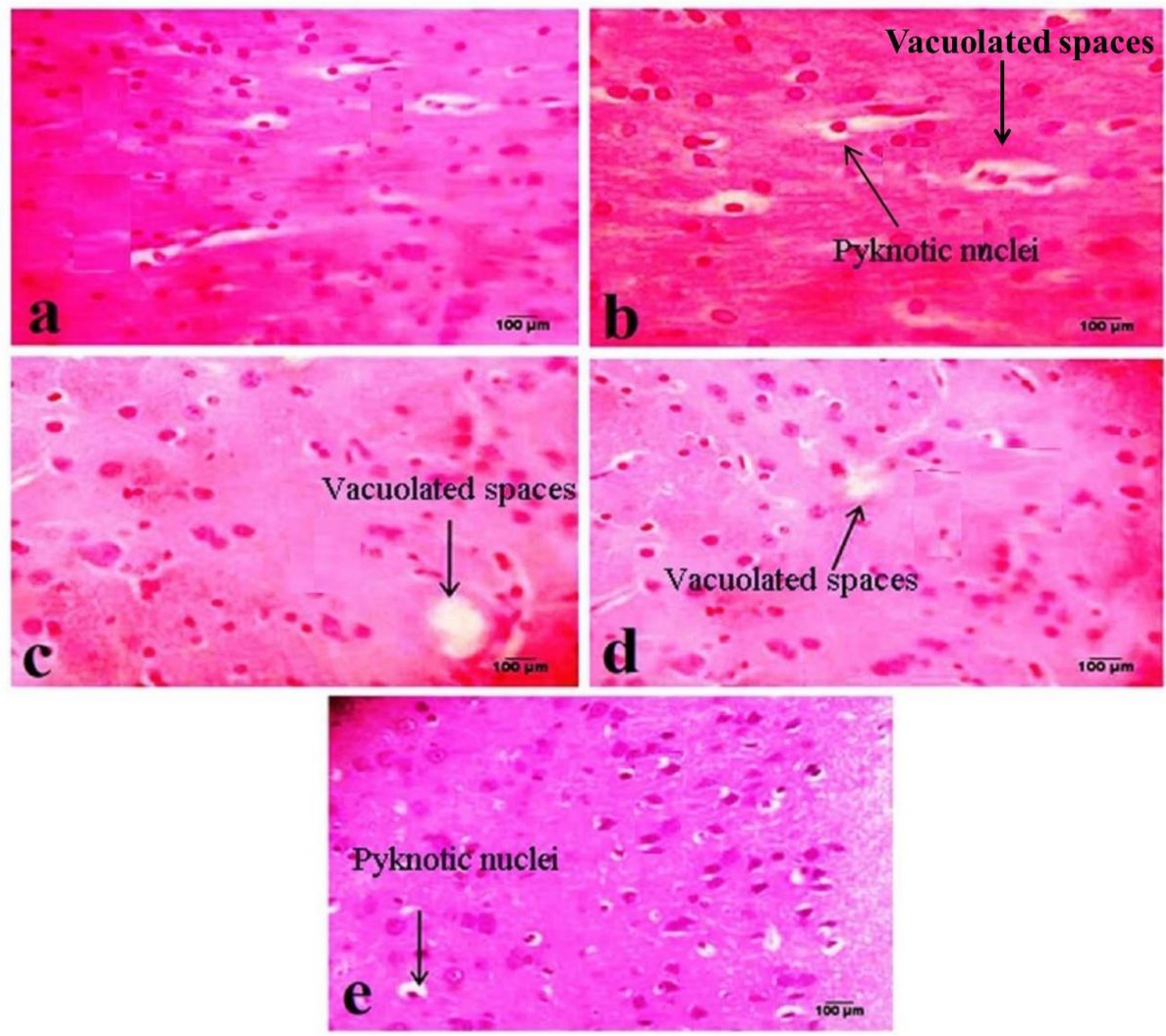

\section{Figure 11}

Histopathological observations of brain tissue: a Sham- operated group showing normal histological picture and no neuronal loss was observed. $b$ marked infiltration of neutrophils, increased intracellular space, pyknotic nuclei, vacuolations and neuronal loss was observed. c PG-8 mg/kg showing moderate reversal of neuronal damage and few vacuolations. d NOS-10 mg/kg showing marked reversal of neuronal damage and partial neuronal loss was observed. e PG+NOS $(8 \mathrm{mg} / \mathrm{kg}+10 \mathrm{mg} / \mathrm{kg})$ showing protection of brain cells from the ischemic damage, improvement in cellular structure and more effective in combination as compared to individual treatment

\section{Supplementary Files}


This is a list of supplementary files associated with this preprint. Click to download.

- SuplementalDatallforPKstudyandvalidation.xlsx

- SupplementalDatalforlnvivostudyGraphpadResults.pzfx

- SupplementalDatallIPKstudy.pzf 